\title{
Kaiser Honorius und der Fall Roms : zur Macht des Glaubens
}

Näf, Beat

Posted at the Zurich Open Repository and Archive, University of Zurich ZORA URL: https://doi.org/10.5167/uzh-90599

Book Section

Published Version

Originally published at:

Näf, Beat (2013). Kaiser Honorius und der Fall Roms : zur Macht des Glaubens. In: Harich-Schwarzbauer, Henriette; Pollmann, Karla. Der Fall Roms und seine Wiederauferstehungen in Antike und Mittelalter. Berlin: De Gruyter, 79-108. 


\section{BEAT NäF ${ }^{1}$ \\ Kaiser Honorius und der Fall Roms: Zur Macht des Glaubens}

\section{Einleitung}

Honorius ist in der Geschichtsschreibung vielfach als unbedeutend und obskur beurteilt worden. Nicht selten wird suggeriert, ein kränkelndes Zeitalter des Niederganges habe die Figur dieses Herrschers hervorgebracht. Sein frühestes Porträt, eine kleine Bronzebüste, die 1901 gefunden wurde und im Burgenländischen Landesmuseum Eisenstadt aufbewahrt wird, ist 1984 als Zeugnis für eine sich auch im Physischen zeigende Degeneriertheit interpretiert worden: Diese Degeneriertheit äussere sich in der Neigung des Kopfes, die einen Schiefhals zeige. ${ }^{2}$ Aus dem Zwielicht der Dekadenz sei er nie herausgetreten. Von Honorius gebe es wie von den übrigen letzten römischen Kaisern nicht viel zu berichten, und kaum Gutes. Ein arroganter Schwächling sei er gewesen, farblos und frömmlerisch, ein Spätling römischer Macht, deren grenzenlose Aggressivität im Zuge der umwälzenden Erfolge der aufsteigenden fremden Völker nun eine Antwort erhielt, die eine von den Zeitgenossen noch nicht wirklich wahrgenommene historische Wende bedeutete. Gerne wird darauf hingewiesen, wie Honorius durch den Willen seines Vaters Theodosius unmündig auf den Herrscherthron gelangte, er kinderlos blieb und sich angeblich wenig um Rom und das Reich kümmerte. Bewirkt habe er nichts, meinte der große Historiker Edward Gibbon. ${ }^{3}$ In seiner meisterhaften Geschichte der Stadt Rom schreibt Ferdinand Gregorovius, bei seinem Tode als 39-Jähriger in Ravenna sei eine „lange und schmachvolle, nur durch den Ruin des Reichs denkwürdige Regierung“ zu Ende gegangen. ${ }^{4}$ Die Maßnahmen seiner Regierung, insbesondere in Britannien und Gallien, so ein moderner Althistoriker, hätten den Zerfall des Imperiums nicht aufhalten können. Bereits die Zeitge-

1 Für Abkürzungen, die im LSJ und OLD fehlen: TLG; A Patristic Greek Lexicon, ed. by G.(eoffrey) W.(illiam) H.(ugo) Lampe, Oxford 1961.

2 Thomas 1984, 157.

3 Zu Gibbon siehe unten im Abschnitt 2. - Er sei ein „ineffective emperor" gewesen - so Moorhead/Stuttard 2010, 8.

4 Gregorovius 1953, 86. 
nossen hätten die Passivität des princeps clausus Honorius als typisches Zeitproblem erkannt. ${ }^{5}$

Wie Gregorovius zu Recht urteilt, steht der Name des Honorius für eine beachtliche Kontinuität. Trotz schwierigster Bedingungen gelang es diesem Herrscher, sich von 395 bis ins Jahr 423 zu halten. Den Fall Roms überstand er genauso wie die zahlreichen Usurpationen und die Entzweiung mit Stilicho. Ernst Stein, Verfasser einer glänzenden Gesamtdarstellung der spätrömischen Zeit, sieht Honorius zwar als „schwachen und tatenscheuen Herrscher", doch zähle er zu einem neuen Kaisertypus, „von dem man wie von dem König der neuzeitlichen konstitutionellen Theorie aussagen“ könne: ",Le roi règne et ne gouverne pas. "“6 Die recht zahlreichen Zeugnisse seiner Regierungstätigkeit in den Rechtsquellen vermitteln indes das Bild eines vergleichsweise durchaus aktiven Kaisers, dem insbesondere Rom wichtig war. ${ }^{7}$ Für den Bereich der Religionspolitik billigt ihm Alexander Demandt im Handbuch der Altertumswissenschaft zu: „So sprunghaft Honorius in seiner Haltung gegenüber Stilicho, Alarich und Placidia war, so konsequent war seine Religionspolitik. " 8

Es gibt jedenfalls etliche zeitgenössische Äußerungen, welche der Wertschätzung des Kaisers deutlich Ausdruck verleihen. Objektiv sind sie nicht, vielmehr durch propagandistische Absichten und durch mehr oder weniger offenes Bemühen um kaiserliches Wohlgefallen geprägt. Trotz aller Katastrophen blieb der Ruhm des Kaisers wichtig. Man buhlte weiterhin um seine Gunst. Die prinzipiell positive Einschätzung des Honorius - bei allen Zwischentönen - offenbar durch eine Mehrheit der Zeitgenossen gründete auf einer geradezu unerschütterlichen Überzeugung, es bedürfe eines römischen Herrschers. Stärker als allen Konkurrenten - einem guten halben Dutzend Usurpatoren - gelang es Honorius und seiner Regierung, die Geltung der Legitimität aufrecht zu erhalten und als Garant des als unersetzlich erachteten römischen Ordnungsmodelles da zu stehen.

Vom Kaiser wurde nicht mehr erwartet, dass er selbst seine Truppen anführte. Seine Sieghaftigkeit, die man noch immer rühmte und zelebrierte, ergab sich vielmehr dadurch, dass er selbst während seiner Regierung die Herrschertugenden der Frömmigkeit, Menschenfreundlichkeit und Milde zeigte. Worte und Gedanken ersetzten Taten. Es reichte aus, wenn die Herrscher die Kriege kannten. Claudian formuliert diese Vorstellung in einem treffenden dichterischen Bild: Theodosius habe seinen Sohn Honorius ermahnt, im Hinblick auf

5 Princeps clausus: Sidon., c. 5.358. Bleckmann 1997, 595: „In der langen Regierung des Honorius [...] wurde der Zerfall des Reichsverbands im Westen trotz vorübergehender Erfolge der Heermeister Stilicho und Constantius entscheidend beschleunigt."

6 Stein 1928, 345.

7 So: Lejdegård 2002.

8 Demandt 2007, 182. 
die kommenden militärischen Aufgaben die Bücher über die alten Feldherren zu lesen und sich in seiner Vorstellung in das historische Latium zurück zu begeben. ${ }^{9}$ Den konkreten Hintergrund solcher Bildungsbeflissenheit erläutert Johannes Lydos: Theodosius habe zum Schutz seiner im Kinderalter stehenden Söhne festgelegt, die Kaiser sollten sich künftig nicht mehr selbst an Kriegszügen beteiligen. ${ }^{10}$

Der Glaube an die Macht des römischen monarchischen Systems in seiner spätantiken Ausprägung blieb weiterhin so dominierend, dass er über die effektiven Auswirkungen einer Mehrfachkrise und der Völkerwanderung hinweg tröstete. Man vergaß, dass der Macht des Kaisers im Westen die Interessen fremder Völker entgegen standen, dass der Herrscher von aristokratischen Familien abhing, geschickten Höflingen und barbarischen Generälen ausgeliefert war, den Goodwill der Armee brauchte, fast ständig durch Usurpatoren bedrängt wurde, die mit ihm verbündete Kirche selbst durch Krisen geschüttelt wurde, die in der Propaganda behauptete Eintracht mit dem Kaiser des viel reicheren Ostens in Wahrheit ein Konkurrenzverhältnis war und überdies immer wieder Versorgungsprobleme bedrängende Notsituationen schufen.

\section{Das propagandistische Bild des im und durch den Glauben sieghaften Kaisers}

Diese Situation war freilich auch zuvor kaum grundlegend besser gewesen, so auch nicht am Ende der 16-jährigen Regierungszeit des Kaisers Theodosius „des Großen“, wie er später und erstmals am Konzil von Chalkedon im Jahre 451 genannt worden ist. Wenn Theodosius noch am letzten Lebenstag zuversichtlich und eindrucksvoll die Macht des Imperiums demonstrierte und in Mailand zur Feier seines Sieges über den Usurpator Eugenius Wagenrennen durchführen ließ, ${ }^{11}$ so war seine umsichtige Nachfolgeregelung doch durch die offenkundige Tatsache belastet, dass nun zwei Kindkaiser ${ }^{12}$ an der Spitze eines fortan stärker als bisher geteilten Imperiums standen. Kein Wunder gab es Zeitgenossen, welche Angst empfanden, die Vernachlässigung der Götter beklagten und an unheilvolle Vorzeichen erinnerten, ja sogar, wie es Eunapios und später Zosimos offen formulierten, in der Regierung des christlichen Herrschers

9 Claud., c. 8 (4 cons. Hon.) 399-400.

10 Lyd., mag. 2.11.

11 Socr., h.e. 5.26.3-4.

12 Den Begriff der „Kinderkaiser“ prägte Werner Hartke in seinem heute durch seinen Anspruch und die gleichzeitige Verstrickung mit der Zeitgeschichte zwiespältig wirkenden Buch: Römische Kinderkaiser. Eine Strukturanalyse römischen Denkens und Daseins, Berlin 1951 - die Stelle wird dort übrigens auch behandelt: $223 \mathrm{f}$. 
Theodosius insgesamt den Anfang einer weiteren Stufe des Niederganges sahen. ${ }^{13}$

Der einflussreiche Mailänder Bischof Ambrosius hingegen trat voller Optimismus in seiner Totenrede auf Theodosius für Zusammenhalt und dynastische Kontinuität ein. Er rief in Aussicht gestellte Vergünstigungen in Erinnerung, nämlich die Amnestie gegenüber den Besiegten sowie Steuererleichterungen. Vor allem wollte er die Loyalität gegenüber den Nachfolgern des verstorbenen Herrschers stärken. Dies waren der zehnjährige Honorius im westlichen Reichsteil und sein sieben Jahre älterer Bruder Arcadius im Osten. Ambrosius erinnerte an den Sieg des Theodosius gegen den Usurpator Eugenius am Frigidus. Er rief auf, dem großen Kaiser im Glauben zu folgen und die Treue zur christlichen Dynastie zu bewahren. So werde man weiterhin siegreiche Herrscher haben. „Der Glaube des Theodosius war euer Sieg - euer Glaube und eure Treue sei die Stärke seiner Söhne!" ${ }^{\text {14 }}$ Die Gläubigkeit der jungen Herrscher und die Treue der Soldaten und Bürger zu ihnen würden die Stärke der Herrscher ausmachen: „Ihr Alter darf keine Bedenken erwecken. Die gläubige Treue der Soldaten bedeutet vollkommenes Alter des Kaisers [... “". ${ }^{15}$

Der Glorifizierung des Honorius dienten erst recht die Werke des Hofdichters Claudian. So soll Honorius in Rom so willkommen gewesen sein, dass man ihn noch stärker herbeisehnte als Trajan und Marc Aurel. ${ }^{16}$ Dabei stehen Trajan, den man gerne auch mit Theodosius verglich, ${ }^{17}$ wie auch Marc Aurel für im Kriege erfolgreiche Herrscher. Bei Marc Aurel erinnert Claudian an die berühmten legio XII fulminata, die angeblich christlich gewesen sein soll. Der verehrungswürdige princeps heißt auch Gestirn des Reiches, gegenwärtiger Genius des Reichs, und er ist ein Gott. ${ }^{18}$

Der Kaiser selbst tritt uns in seinen Münzlegenden mit der üblichen Propaganda entgegen. Legenden, welche militärische Werte verkörpern oder militärfreundlich sind (wie: concordia militum, fides exercitus, genius exercitus) dünnen bereits im ausgehenden 4. Jahrhundert aus, und es bleibt schon bei den Vorgängern des Honorius allein die Erwähnung der virtus militum. Die (Rückseiten-)Legende Victoria Augustorum (die auch von Theodosius und Eugenius benützt worden war) auf Goldsolidi sei im Hinblick auf das im Folgenden weiter unten behandelte Consulardiptychon des Probus hervorgehoben. Sie ist kombiniert mit einer Darstellung des Kaisers in militärischer Tracht. Der Kaiser setzt den linken Fuss auf einen Barbaren. In der Rechten hält er das

13 Zos. 4.59.3-4 und zur Einschätzung der Machtlosigkeit von Honorius und Arcadius Eunap., fr. 62.1 Blockley.

14 Ambr., obit. Theod. 8.

15 Ambr., obit. Theod. 6.

16 Claud., c. 28 (6 cons. Hon.) 331-350.

17 (Ps.-)Aur. Vict., epit. Caes. 48.8-10.

18 Döpp 1980, 240. 
Labarum, in der Linken einen Globus, auf dem eine kleine Victoria steht. Obschon es sich um einen bereits traditionellen Typus handelt, hat man ihn indes wohl zu Recht trotzdem mit den Vorgängen der Jahre 394/95 sowie der Formulierung Claudians Latiae sublimis signifer in Zusammenhang gebracht. ${ }^{19}$ Eine ähnliche Rückseitendarstellung ist auch für die Münzen benutzt worden, welche versehen mit der Legende Triumfator Gent Barb den Sieg über die Goten bei Verona und Pollentia von 402 feierten und zum Teil wohl zum donativum für die Truppen Stilichos gehörten. ${ }^{20}$ Voller Enthusiasmus schrieb Prudentius im Sommer 402 in seinem Kampfgedicht Contra Symmachum von einem jungen Führer des Heerzuges und Imperiums, der durch Christus stark sei (Christipotens). Nach dem Gebet vor den Altären habe man noch vor den Drachenzeichen das Christusmonogramm vorangetragen. ${ }^{21}$ Das Bild eines kriegerischen und mit der Hilfe Christi siegreichen Kaisers zeigt das Consulardiptychon des Flavius Anicius Petronius Probus ${ }^{22}$ aus dem Jahre 406. In der Rechten hält der Kaiser ein Labarum mit dem Text: In nomine Christi vincas semper. Die Linke hält einen Globus. Auf diesem steht Victoria und streckt dem Kaiser mit der Rechten einen Kranz entgegen. Mit einer Siegespalme in der linken Hand unterstreicht sie die Gewissheit des Erfolges.

Diese Tradition der Kaiserdarstellung ist freilich keineswegs auf Honorius beschränkt und findet sich vor und nach ihm. Unter anderem hat man denn erwogen, die mächtige Bronzestatue des bartlosen und diademgekrönten Kolosses von Barletta mit Tunica, Panzer und Paludamentum sowie Globus in der Rechten und Kreuz in der Linken als Honorius zu interpretieren. ${ }^{23}$ Ähnlich wie der Kaiser liebten es auch hohe Beamte, so der Stadtpräfekt von Rom, sich in militärischem Habitus zu zeigen. Das Diptychon des vicarius urbis Romae Rufius Probianus führt dies vor. Der hohe Amtsträger ist einmal mit der ihm zukommenden zivilen Toga, dann in seinem Dienstkleid, der Chlamys, abgebildet. $^{24}$ Dieser Dienst bestand indes nur noch dem Namen nach in einer militärischen Amtsgewalt. 407 schrieb Paulinus von Nola begeistert vom siegreichen Kindkaiser (annis tener idem fortis in armis), der die Macht Gottes auf seiner Seite hatte. ${ }^{25}$ Ein Jahr zuvor hatte eben Stilicho Radagais bei Faesulae besiegt. Der Stadtpräfekt des Jahres 406 Flavius Pisidius Romulus ehrte auf

19 Claud., c. 28 (6 cons. Hon.) 22. RIC X. 123-137. 317-342. pl. 34-42.

20 J.-P. Callu: „Triumfator Gent Barb: la monnaie de la défaite d'Alaric“, in: Giorcelli Bersani (Hg.) 2004, 25-37; darunter RIC X. 320 No. 1216. 325 f. No. 1260-1261. 328 No. 1292.

21 Prud., c. Symm. 2.709-714.

22 Delbrueck 1929, 84-87 (im Kirchenschatz von Aosta); Kiilerich/Torp 1989, 368-371.

23 Vgl. Purpura 1993; Ruck 2007, v. a. 259 f. (Ausschluss, d.h. keine Behandlung des Kolosses von Barletta).

24 Delbrueck 1929, 250-256 (Nr. 65); vgl. Warland 1994, 187 f.

25 Paul. Nol., c. 21.20-24. 
einer Inschriftenbasis für eine Statue des Honorius auf dem Forum Romanum fides und virtus der Kaiser Arcadius, Honorius und Theodosius II. und ihrer treuen Truppen anlässlich dieses Erfolges. Die Inschrift nannte ursprünglich auch Stilicho. Doch wurde dessen 408 missliebig gewordener Name dann getilgt. $^{26}$

Orosius sah darin das Wirken Gottes, der den frommen Kaiser Honorius belohnt habe:

Vor allem aber geschah dies, dass die bei einem Herrscher zu bewundernde Selbstbeherrschung des Kaisers Honorius und sein außerordentlich frommer Glaube nicht wenig göttliches Erbarmen verdienten. ${ }^{27}$

Die von Orosius geschilderte Verbindung von Kaiser, Christus und Roma hatte auch bereits schon Prudentius begeistert: „Herrscher der Welt wirst Du sein,“ spricht er den Kaiser an, „mit Christus vereinigt für immer, und unter seiner Leitung führst du empor zum Himmel mein Reich. ${ }^{\text {'28 }}$

\section{Honorius - Verurteilung eines Herrschers}

Für Gesetzgebung ${ }^{29}$ und Personalpolitik ${ }^{30}$ des Honorius fehlen solch enthusiastische Urteile der Zustimmung, vielleicht auch deshalb, weil kaiserliche Entscheidungen in diesen Bereichen vielfach mit Härten einher gingen, ja Terror ausübten. Propagandistisch strichen Herrscher freilich ihre bumanitas heraus oder sprachen von clementia nostra, so auch Honorius. Diese Kombination scheint im Sinne der Regierung gewirkt zu haben. Machtpolitisch betrachtet zeugen die Maßnahmen des Honorius von einem nicht ungeschickten und angesichts der diffizilen Verhältnisse und der beschränkten Machtmittel des Hofes geradezu angemessenen Lavieren. Dabei scheute Honorius vor harten Strafen und brutaler Gewaltanwendung nicht zurück. Zu einer später zwar in manchen Quellen nicht selten weitgehend beschwiegenen, aber unmöglich zu kaschierenden Katastrophe führten der Zwist und die Hinrichtung des Stilicho, seiner Frau Serena und ihres Sohnes Eucherius im Jahre 408. Die Anhänger des Honorius mochten noch so sehr Stilicho anschwärzen. Offensichtlich waren Menschlichkeit und Moral durch Honorius und seine Befehlsempfänger krass missachtet worden. Als Stilicho Zuflucht in einer als unantastbar geltenden Kirche gesucht hatte, lockte man ihn hinaus und tötete ihn; bei seinem Sohne

26 CIL VI.31987 = ILS 799. Vgl. Chastagnol 1962, 263; Bauer 1996, $20 \mathrm{f}$.

27 Oros., hist. 7.37.11.

28 Prud., c. Symm. 2.758-760.

29 Die Gesetze in chronologischer Reihenfolge in elektronischer Form bei Honoré 1998.

30 Vgl. von Haehling 1978, 593-595. 
Eucherius respektierte man den Schutz der Kirche gleichfalls nicht wirklich. ${ }^{31}$ Dabei war es gerade Honorius gewesen, der das Kirchenasyl gesetzlich gefördert hatte. ${ }^{32}$ Noch Jahre später legte Honorius in einer für die Zukunft dieser neuen Einrichtung bahnbrechenden Konstitution fest, die „Heiligkeit der kirchlichen Würde" erstrecke sich sogar bis fünfzig Schritte vor die Türe einer Basilika. ${ }^{33}$

Das blutige Geschehen war offenkundig zugleich eine grauenhafte Familientragödie, welche die Erhaltung der kaiserlichen Dynastie des Theodosius bzw. des Valentinian ernsthaft gefährdete. Von Thermantia, seiner Frau, die eine Tochter des Stilicho und der Serena war, trennte sich Honorius. Er heiratete nicht mehr und blieb kinderlos; denn schon seine erste Ehe mit Maria gleichfalls einer Tochter des Stilicho und der Serena - hatte keinen Thronfolger hervorgebracht. Immerhin setzten Galla Placidia, die Halbschwester des Honorius, sowie im Osten Theodosius II. die dynastische Kontinuität fort.

Das Ende des Stilicho öffnete den Weg zur Eroberung Roms durch Alarich. Nichtsdestotrotz trat Honorius weiterhin mit dem Anspruch auf Sieghaftigkeit in Erscheinung. So heißen in einem in Ravenna erlassenen Gesetz vom 14. Oktober 410 Honorius und Theodosius pii felices victores ac triumphatores semper Augusti. ${ }^{34}$ Eine solche Diskrepanz zwischen Anspruch, Propaganda und Wirklichkeit müsste, so empfinden wir es heute, jedem halbwegs klaren Beobachter ins Auge stechen. Noch anstößiger erscheint es vielen modernen Historikerinnern und Historikern, dass Honorius sein Leben in Ravenna führte, wobei man unterstellt, der purpurgeborene Herrscher habe sich abgeschirmt und zurückgezogen um nichts gekümmert. Milder urteilend hat man die Schwächen und Widersprüche der Regierung des Honorius indes vielfach mit dessen jungem Alter erklärt.

Sébastien Le Nain de Tillemont zweifelte an den Fähigkeiten des Kaisers und klagte in seiner großen Histoire des Empereurs, der quellenreichsten Gesamtdarstellung der Vorgänge der Zeit: „Malheur en bien des manieres aux Etats qui ont des enfans pour Princes! ${ }^{\text {“35 }}$ Schonungslos und voll schwarzer Ironie zeichnete Edward Gibbon ein vernichtendes Porträt des in seinem Hofe gefangenen Kaisers:

Seine Untertanen, die den Charakter ihres jungen Herrschers eingehend studierten, stellten fest, dass Honorius keine Leidenschaften und mithin auch keine Talente

31 Zos. 5.34.3-5. Philost, h.e. 12.3 - gemäss Zos. 5.35.4 respektierte man das Asyl; vgl. dann 5.37.4 (Ermordung); die übrigen Quellen berichten vom Tode des Eucherius, aber nicht von seiner Kirchenflucht.

32 Cod. Theod. 16.6.4.2 (12.2.405).

33 Sirm. 13 (21.11.419).

34 Seeck 1919, 320 (Cod. Theod. 16.11.3 = gesta coll. Carth. 1.4; 3.24,29 (a. 411) [Mansi vol. 4, p. 53, 185d, 186]). Vgl. später Avell. 14.3 (29.12.418); 35.1 (7.4.419); 37.1 (Juli 419).

35 Tillemont 1732, 485. 
besaß und aufgrund seiner schwächlichen und trägen Veranlagung ebenso unfähig war, den Pflichten seiner Position zu genügen wie die Freuden seines Alters zu genießen. In früher Jugend gelangen Honorius einige Fortschritte im Reiten und Bogenschießen, aber schon bald gab er diesen anstrengenden Zeitvertrieb auf, und die Kurzweil, das Federvieh zu füttern, bildete das ernste und tägliche Geschäft des Monarchen des Westens, der die Zügel des Reiches der festen und kundigen Hand seines Vormunds Stilicho überließ. Die Erfahrung der Geschichte nährt die Vermutung, dass der im Purpur geborene Fürst eine schlechtere Erziehung genoss als der geringste Bauer in seinem Herrschaftsgebiet ... Der Sohn des Theodosius ... verträumte sein Leben als Gefangener in seinem Palast, ein Fremder in seiner Heimat, und als geduldiger, beinahe unbeteiligter Beobachter des Ruins des westlichen Reiches ... In der bewegten Geschichte seiner achtundzwanzig Jahre dauernden Regierung werden wir selten Veranlassung finden, den Namen des Kaisers Honorius zu erwähnen. ${ }^{36}$

Noch negativer urteilte in ihrer Biographie der Galla Placidia Maria Assunta Nagl, eine Autorin, die auch in der katholischen Frauenbewegung aktiv gewesen war:

Honorius war ganz der Indolenz verfallen, die schon an seinem Vater ab und zu hervortrat ... Bei dem Sohne ... nimmt die Veranlagung ... die klägliche Gestalt vollkommener Unfähigkeit zu jeglicher Tätigkeit an. ${ }^{3}$

Henry Benrath (Pseudonym für Albert H. Rausch) ließ in einem Roman seine Galla Placidia nach dem Tode des Honorius klagen:

... ein schönes, ein männliches Leben zu führen, war ihm nicht vergönnt ... Was könnte einen Kaiser Schlimmeres treffen? Einen - römischen Kaiser! $!^{38}$

Für den Schweizer Dramatiker Friedrich Dürrenmatt muss der verträumte Honorius so farblos und in dieser für die Mächtigen dieser Erde etwas herausstechenden Andershaftigkeit zugleich doch so anziehend gewesen sein, dass er die Honorius zugeschriebene Hühnerzucht auf Kaiser Romulus und die Ereignisse des Jahres 476 übertrug. ${ }^{39}$ Die Legende vom hühnerzüchtenden Kaiser fand auch Eingang in die bildende Kunst: Bekannt geworden ist vor allem das 1883 entstandene Gemälde von John William Waterhouse, The Favorites of the Emperor Honorius. Die negative Charakterisierung geht zurück auf den Historiker Prokop und seine Quellen. Dieser erzählt in seinen Vandalenkriegen folgende Anekdote:

Kaiser Honorius residierte früher in Rom, hatte keine kriegerischen Unternehmungen im Sinn, sondern war, wie ich glaube, zufrieden, wenn man ihn in seinem Palaste in Ruhe ließ. Auf die Kunde jedoch, die Barbaren stünden mit einem großen Heere schon nicht mehr fern, sondern irgendwo im Gebiete der Taulantier, verließ

36 Gibbon 2003, 216 (Honorius: Kapitel 26-32); Tillemont 1732, 485.

37 Nagl 1908, 12.

38 Benrath 1937, 281.

39 Dürrenmatt 1980. 
er seine Residenz und floh in aller Eile nach Ravenna, einer befestigten, unmittelbar am Ende des Jonischen Meerbusens gelegenen Stadt. Einige behaupten sogar, er habe selbst die Barbaren herbeigerufen, da sich seine Untertanen gegen ihn empört hätten. Doch scheint mir, soweit sich Menschenart beurteilen lässt, diese Annahme nicht glaubwürdig. ${ }^{40}$

Prokop berichtet weiter, dem im sicheren Ravenna weilenden Kaiser habe ein Eunuche, der für die Hühner und Vögel am Hofe gesorgt habe, mitgeteilt, Rom sei durch Alarich eingenommen worden. Der Kaiser habe mit den Worten reagiert: „Aber er hat doch erst jüngst noch aus meinen Händen gefressen!“41 Sein großer Hahn namens Roma sei ihm wichtiger als die Hauptstadt gewesen. Bei Prokop findet sich im Weiteren auch die Angabe, es sei die vornehme Anicierin Proba gewesen, welche ein Stadttor geöffnet habe, so dass die Westgoten Alarichs Rom im August 410 so leicht einnehmen konnten. Weil die Anicier bekannterweise auf der Seite des Honorius standen, richtet sich wohl auch diese Angabe gegen Honorius, dem Prokop es immerhin nicht zutrauen wollte, die Barbaren selbst herbeigerufen zu haben. Vielleicht ging es Prokop um die Herausstreichung der Dummheit (amathía) des Kaisers wie aber auch der Römer, die ahnungslos 300 Sklaven aufnahmen, ein Geschenk Alarichs, ironischerweise in der Größenordnung des römischen Senats. Die Sklaven überfielen dann die Wachen, machten diese nieder und öffneten die Tore. Der Vorwurf der Dummheit ist in der Kaiser- und Oberschichtenkritik nicht selten anzutreffen. Aber vor allem sind die anekdotischen Geschichten zum Ende Roms komisch und voller Häme. Ein Vogelwärter und Eunuche bringt die Katastrophenmeldung, und der Kaiser weiß sie gerade so wenig zu verstehen, wie einst manche Römer Auspizien zu lesen vermochten, ein Thema, über das schon Cicero - und auch nicht als erster - spottete. ${ }^{42}$ Ein wesentlich schlimmeres Bild malte Zonaras. Danach sei Honorius schuld am Fall Roms. ${ }^{43}$

\section{Der Fall Roms 410: zeitgenössische Betroffenheit und die Frage nach der Rolle des Honorius}

Die angebliche Gleichgültigkeit - ja gar Schuld - des Herrschers steht in Kontrast zu manchen zeitgenössischen Zeugnissen tiefer Betroffenheit über den Fall Roms. Diese zeigen, wie wichtig Rom nach wie vor war: Dass der Kaiser die Hauptstadt vernachlässigt hätte, wollte man sich dabei nicht vorstellen. „Was

40 Prok., Vand. 1.2.8-10, deutsch O. Veh.

41 Prok., Vand. 1.2.26.

42 So: Cic., div. 1.25-29; 2.72. Vgl. auch Engels 2009.

43 Martelli 1981 vermutet eine Entstehung dieses Bildes in der Zeit des Usurpators Johannes Primicerius 423-425. 
bleibt noch heil, wenn Rom untergeht? (Quid salvum est, si Roma perit?)“ befürchtete Hieronymus ein Jahr zuvor, und als das Schreckliche passiert war, klagte er: „Die Stimme stockt mir, und vor Schluchzen kann ich nicht weiterdiktieren: Die Stadt Rom ist eingenommen, die zuvor die ganze Welt besiegt hatte. ${ }^{\text {"44 }}$ Augustin war gleichfalls tief bewegt, reagierte aber weit gelassener und zugleich auch sehr viel ausführlicher. Sein monumentales Werk De civitate Dei wie auch seine Predigten nahmen den Fall Roms als Chance wahr, um zu lernen. Es war nichts Ungewöhnliches, dass Rom gefallen war. Schon zweimal in der Geschichte hatte Rom ja vergleichbare Katastrophen erlebt. Nun aber, da man die christliche Heilsbotschaft kannte, musste man lernen. Die Strafe der Einnahme Roms sollte von den Römern im Geiste der Buße und der Besinnung getragen werden. Kaiser Honorius wird von Augustin kaum erwähnt. Er wusste von seinem Rombesuch 403/04, und er sah ihn wohl ähnlich wie Theodosius den Großen, der an einer bekannten Stelle der Civitas Dei gerühmt wird. ${ }^{45}$ Die kaiserlichen Tugenden zeigen sich in den Schriften Augustins vor allem im Vorgehen gegen die Donatisten. ${ }^{46}$

Der Historiker Orosius relativierte gleichfalls die Folgen des Geschehens von 410. Eine Schuld des Honorius durch die Beseitigung des Stilicho will er nicht sehen. Rom fiel, weil es seine Strafe verdiente. ${ }^{47}$ Der Einbruch der Barbaren endete seiner Meinung nach mit einem positiven Ergebnis, wurden doch so die „Kirchen Christi von Hunnen, Sueben, Wandalen, Burgundern und verschiedenen unzähligen Scharen von Gläubigen angefüllt ${ }^{\text {“. }}{ }^{48}$ Pelagius sah in der Katastrophe das Versagen des Adels und der Amtsträger und hob dem gegenüber die Bedeutung einer asketischen, christlichen Lebensweise hervor. ${ }^{49}$ Papst Innocenz I. (402-417) schreibt kühl und ganz nebenher von der „Verwirrung des Barbarensturmes", der einen zu erörternden Gesetzesfall gezeitigt habe: der Mann einer Frau, die von den Germanen längere Zeit in Gefangenschaft gehalten worden war, hatte sich ein zweites Mal verheiratet. ${ }^{50}$ Der heidnische Stadtpräfekt des Jahres 417, der Gallier Rutilius Namatianus, gibt zu erkennen, dass man auch nach dem Fall Roms mit dessen Macht und Zukunft

44 Hieron., epist. 23.16 (vgl. Luc. 5.274); 127.12. Zu Hieronymus' Versagen der Stimme vgl. Ricci 213 in diesem Band. Vgl. u. a. Demandt, 2007, 178 f. mit der dort angegebenen Literatur sowie weiter: Fischer 1947; Heinzberger 1976; Piganiol 1964; Leppin 1996, 143-145; Feichtinger 1998; Goetz/Patzold/Welwei 2007, 313-352; Saint Augustin 2004.

45 Aug., civ. 5.26.

46 Aug., epist. 185; contra litteras Petiliani; contra litteras Parmeniani. Vgl. Klein 2006.

47 Oros., hist. 7.38.5-7.

48 Oros., hist. 7.41.8.

49 Pelag., epist. ad Demetr. 30 (PL 30, 45D-46 A = 33, 1120).

50 Epist. pontif. 36 (Jaffé/Kaltenbrunner 313) (an Probus); Caspar 1930, 300. 
rechnete. Die Schuld am Debakel sieht er beim Verräter Stilicho, nicht bei Honorius.

Im Folgenden soll weiter dargelegt werden, wie Honorius sich gegenüber Rom verhalten hat und dass möglicherweise die negative Einschätzung seiner Person und Politik manchmal zu weit gegangen ist. Man hat zuweilen übersehen, dass Honorius wie Rom für die Zeitgenossen wesentliche Symbole eines Glaubens und einer Verbundenheit zum römischen Ordnungsmodell bedeuteten. Der Vater des Theodosius, von dem es hieß, er sei mäßig gebildet, ${ }^{51}$ sowie der wort- und schriftgewaltige Bischof Ambrosius von Mailand hatten die Verbreitung einer solchen Haltung erfolgreich gefördert. Honorius setzte ihre Tradition fort, zwar weniger machtvoll und erfolgreich, aber doch im gleichen Geiste. Dabei stand er in Konkurrenz mit dem Ostkaiser und diversen Usurpatoren. Einer dieser Usurpatoren, ein ehemaliger Mönch, Constans, der ältere Sohn des Usurpators Constantinus III., kämpfte in Spanien gegen Honorius mit unter den Goten gewonnenen Anhängern, die nach Honorius Honoriaci genannt wurden. ${ }^{52}$ Konkurrenz gab es ebenso unter weiteren Exponenten der Eliten. Auch sie propagandierten ähnliche oder vergleichbare Symbole und Leistungen, insbesondere Stilicho und römische, heidnische Aristokraten, in einem gewissen Sinne aber auch Alarich und Athaulf. Gerade die Anführer der Westgoten waren durchaus daran interessiert, das römische Modell und seine Grundideen zu benutzen.

\section{Honorius und Rom bis 408}

Kein Kaiser seit Maxentius und Konstantin war so häufig in der alten Hauptstadt wie Honorius. ${ }^{53}$ Bereits als Kind nahm ihn sein Vater Theodosius 389 nach Rom mit, auch wenn er ihn aus Konstantinopel holen lassen musste, um am 13. Juni den Triumph über den Usurpator Maxentius zu feiern. ${ }^{54}$ In den Jahren danach fällt auf, dass wir nichts über ein Auftreten des Honorius im Zuge von Vorgehensweisen in Rom erfahren, welche der heidnischen Aristokratie missfallen mussten. Nach der Niederwerfung des Eugenius 394 blieb er wohl in Mailand, als Theodosius den Triumph in Rom feierte. Wie Zosimos beklagt, seien damals heidnische Priester und Priesterinnen vertrieben worden. ${ }^{55}$ Insbesondere Stilicho und seine Frau Serena hätten sich durch ein pietätloses

51 (Ps.-)Aur. Vict., epit. Caes. 48.11.

52 Oros., hist. 7.40.7.

53 Elbern 1990, 40 f.; Gillett 2001, Lejdegård 2002, 45-59.

54 Chronica minora 1 (MGH AA 9), 245 (Consularia Constantinopolitana), 298 (Consularia Italica); 2 (MGH AA 11), 62 (Marcellinus Comes); Socr., h.e. 5.14.3; Claud., c. 28 (6 cons. Hon.) 53-76, 424.

55 Zos. 5.38.2. 
Vorgehen hervorgetan: So habe Stilicho befohlen, die Türen auf dem Kapitol, die mit Gold verkleidet gewesen seien, abzuschaben. ${ }^{56}$ Im Namen der neuen Regierung des Honorius und Arcadius versuchte man jedenfalls nach dem Sieg über Eugenius einen Neuanfang zu machen: Der Name des von Eugenius ernannten Prätorianerpräfekten und Konsuln (sine collega), des Virius Nicomachus Flavianus, sollte gelöscht werden. In den Konsullisten blieben Honorius und Arcadius, die Theodosius damals im Gegenzug als Konsuln bestimmt hatte. ${ }^{57}$

Trotzdem ist nicht zu übersehen, dass man den Ausgleich mit der stadtrömischen Aristokratie suchte. Die Konsulernennung von 395 (die beiden jungen Anicier Olybrius und Probinus) war eine deutliche Ehrung des römischen Senats; darüber hinaus sollten jene Persönlichkeiten, die den Aufstand des Eugenius unterstützt hatten, rehabilitiert werden. ${ }^{58}$ Honorius selbst war bei der Feier des Konsulats nicht zugegen. Claudian feierte die beiden Anicier in einem Panegyricus, ein Jahr danach trug er als Gesandter des römischen Senats in Mailand anlässlich des dritten Konsulats des Honorius in Mailand ein Gratulationsgedicht vor. ${ }^{59}$ Auf ein „skandalöses Desinteresse“ in der Regierungszeit der Kaiser Honorius und Arcadius an der urbs aeterna zu schließen - so eine Studie -, das ,seinen deutlichsten Ausdruck in den nach römischen Aristokraten benannten for " in Rom besitze, charakterisiert meines Erachtens die damaligen Verhältnisse nicht richtig. ${ }^{60}$ Kaiser und Aristokratie waren vielmehr gegenseitig aufeinander angewiesen, und sowohl unter den einzelnen Stadtpräfekten, die bei den prominenten Baumassnahmen hauptsächlich in Erscheinung traten, wie auch unter der Aristokratie hatte Honorius ja gerade seine Stützen - so die Anicier - oder musste sie suchen - so bei den der Dynastie des Theodosius wohl ablehnend gegenüberstehenden Altgläubigen. Wenn er auf einem der neuen Foren einen an den Stadtpräfekten Nicomachus Flavianus gerichteten Erlass anbringen ließ, der Interessen der navicularii schützte, zeigt dies deutlich, dass der Kaiser in Rom präsent sein wollte und der heidnische Stadtpräfekt umgekehrt des Kaisers bedurfte. ${ }^{61}$

Im Zuge der Bemühungen und Auseinandersetzungen um Macht und Einfluss wurde insbesondere auch auf ein gutes Verhältnis zum Senat geachtet. Eutropius hatte es fertig gebracht, Stilicho mit Hilfe des östlichen Senats 397/98 zum Staatsfeind erklären zu lassen. ${ }^{62}$ Umgekehrt unterstützte der westliche Senat

56 Zos. 5.38.3-5.

57 Cod. Theod. 15.14 .9 (21.4.395) an den Stadtpräfekten Andromachus. Vgl. Hedrick 2000, $94 \mathrm{f}$.

58 Vgl. u.a. Hedrick 2000, $94 \mathrm{f}$.

59 Vgl. Döpp 1980, 43-60; 77-84.

60 Mayer 2002, 204.

61 Cod. Theod. 13.5.29; Chastagnol 1962, 243; Niquet 2000, 215.

62 Zos. 5.11.1. 
damals Stilicho im Kampfe gegen Gildo, indem er diesen gleichfalls zum Staatsfeind erklärte. ${ }^{63}$ Claudian zeigt in Passagen seiner Panegyrik im Dienste Stilichos wie des Honorius recht deutlich, dass die Pflege eines guten Verhältnisses zum Senat auch in den folgenden Jahren wichtig geblieben ist. So erwähnt Claudian auch die alte Victoriastatue im Senatsgebäude voller Achtung. Sie erscheint nicht mehr wie in den Zeiten des Streites zwischen Ambrosius und Symmachus als Symbol für Gegensätze religiöser Haltungen, sondern als ein in der Tradition verwurzeltes Zeichen militärischer Sieghaftigkeit in Gegenwart und Zukunft. Der Glaube an diese Sieghaftigkeit wird mit Hilfe des Senats bestärkt. Mit den Konsulaten des Feldherrn Stilicho im Jahre 400 beziehungsweise des Imperators Honorius 404 kann überdies veranschaulicht werden, wie durch den erfolgreichen Krieg Frieden garantiert wird. ${ }^{64}$

$\mathrm{Zu}$ Beginn seiner Herrschaftszeit weilte Honorius in Mailand. Als Alarich 401 bis 402 die Alpen überquerte, zog er sich nach Ravenna zurück und verstärkte dort die Stadtmauern. ${ }^{65}$ Prokop spricht von einer Flucht, ${ }^{66}$ aber Honorius hat in Wahrheit eine höchst vernünftige Entscheidung getroffen. Ravenna besaß einen vorzüglichen Hafen und war näher beim Osten. Palast und eine Kirche konnten im Schutze der Mauern unbehindert errichtet werden. Honorius wählte eine bessere Residenzstätte, so wie das frühere gleichfalls aktive Herrscher an anderen für sie günstig gelegenen Orten in ähnlicher Weise getan hatten. Eine stärkere Vernachlässigung Roms als bei früheren Kaisern kann daraus nicht abgeleitet werden. ${ }^{67}$ So richtet sich bezeichnenderweise das erste in Ravenna erlassene Gesetz vom 6. Dezember 402 an den Stadtpräfekten Caecina Decius Albinus iunior, der zuvor eine Funktion am Hofe innegehabt hatte. ${ }^{68}$ Von diesem heidnischen Stadtpräfekten, dessen Bildung Symmachus und Macrobius rühmen, ist unter anderem eine Statuenbasis zu Ehren des Arcadius erhalten. ${ }^{69}$

Für das sechste Konsulat des Honorius wurde in Rom 404 ein triumphaler Anlass organisiert, der durch einen Panegyricus des Claudian eindrucksvoll bezeugt ist. Der erste Teil des Gedichtes schildert die historischen Ereignisse der Zeit, der zweite würdigt den Aufenthalt in Rom. Die Reise von Ravenna nach Rom und die Ankunft in der alten Hauptstadt werden detailliert beschrieben. Honorius spricht auf dem Forum zum Volk, in der Curia zum Adel; er zieht in den Kaiserpalast ein und veranstaltet Spiele. Rom sei nach wie vor die für die

63 Symm., epist. 4. 5.

64 Claud., c. 24 (cons. Stil. 3) 202-222; c. 23 (cons. Stil. 3 praef.) 19; c. 28 (6 cons. Hon.) 597-602, 653.

65 Deichmann 1969, 39; Deliyannis 2010, 51-54.

66 Prok., Vand. 1.2.8-9.

67 Vgl. Deliyannis 2010, 46-48.

68 Cod. Theod. 7.13.15 (Stellen von Rekruten).

69 CIL VI.1192 = ILS 796. Vgl. Chastagnol 1962, $259 \mathrm{f}$. 
Herrscher der Welt einzig geziemende Heimat. ${ }^{70}$ Auch Augustin scheint in einer Predigt auf den eindrücklichen Rombesuch des Honorius angespielt zu haben. Dabei nimmt er ihn als Zeugnis des Triumphes des Christentums wahr. Bemerkenswerterweise erwähnt Augustin, dass das Grabmal eines großen heidnischen römischen Kaisers, nämlich Hadrians, in unmittelbarer Nähe zu St. Peter liegt. Könnte dies eine Anspielung auf die Wahl des Honorius sein, dort das Mausoleum seiner Familie einzurichten und den paganen Kaiserkult durch das Christentum zu ersetzen? Augustins Worte lauten:

Gerade kommen die Könige nach Rom. Ein großes Ereignis, Brüder (...) Dort befinden sich die Tempel der Kaiser, die in ihrer Überheblichkeit von den Menschen göttliche Ehren für sich verlangten (...) Dort ist das Grab des Fischers, dort der Tempel des Kaisers. Petrus ist dort im Grab, Hadrian ist dort im Tempel. Der Tempel des Hadrian, das Grabmal des Petrus. Der Kaiser ist gekommen. Lasst uns sehen, wohin er geeilt ist, wo er niederknien wollte (...) Er legt sein Diadem nieder, schlägt sich an die Brust, wo der Körper des Fischers liegt (...). ${ }^{71}$

Honorius soll damals die Gladiatorenspiele abgeschafft haben, berichtet Theodoret. ${ }^{72}$ Claudian stellt es hingegen so dar, als habe Honorius die Stadt respektiert, wie sie gewesen sei. Durch seine glänzende und ruhmvolle Geschichte war Rom, das Zentrum des Reiches, so wie es war, offenkundig und unbestritten die ideale und privilegierte Residenz schlechthin. Von den Römern wurde Honorius begeistert empfangen, auch wenn er auf die üblichen Geldgeschenke verzichtete. ${ }^{73}$ Im Jahre 404 wurden auch mehrere Gesetze in Rom erlassen, ebenso dann wieder 407 und $408 .^{74}$ Den nach dem Ende Stilichos Proskribierten drohte ein an den Prätorianerpräfekten Theodorus, den Nachfolger des Flavius Macrobius Longinianus, gerichtetes Gesetz Deportation an, wenn diese entweder den Hof oder Rom zu betreten wagten. ${ }^{75}$

70 Claud., c. 28 (6. cons. Hon.) 39-41: Non alium certe decuit rectoribus orbis / esse larem, nulloque magis se colle potestas / aestimat et summi sentit fastigia iuris.

71 Augustin d'Hippone, Vingt-six sermons au peuple d'Afrique, éd. par François Dolbeau, (Collection des Études Augustiniennes, Série Antiquité 147), Paris 1996, 265 f. = Mainz Nr. 61 = Dolbeau Nr. 25, Sermo sancti Augustini cum pagani ingrederentur, $25 \mathrm{f}$. Zuerst in: Revue des Études Augustiniennes 37, 1991, 37-77; vgl. Fraschetti 1999a und b, 261-265; Sivan 2011, $71 \mathrm{f}$.

72 Theod., h.e. 5.26 .

73 Claud., c. 28 (6. cons. Hon.) 604-610.

74 404: Cod. Theod. 7.5.2 (Aufhebung aller Befreiungen von munera für die Verpflegung des Heeres); 8.5.65 (cursus publicus); 14.1.4 (Rechte von Angehörigen der Korporationen Roms in Rechtsverfahren); 16.8.16 (Juden und Samaritaner im kaiserlichen Dienst); 16.8.17 (Juden). - 407: 7.20.13 (Fragen der militärischen Rangordnung); 16.2.38 (kirchliche Privilegien); 16.5.40 (Häretiker). 16.5.41 (Häretiker); Sirm. 12 (Häretiker). 408: 1.20 .1 (Unparteilichkeit der Richter); 14.4 .8 (suarii).

75 Cod. Theod. 9.40.20. Zur Konstitution gehören auch 9.42.22 und 7.21.4. 
In der Zeit des Honorius restaurierte man die Basilica Iulia, die Thermen des Decius, das Theater des Pompejus, die Aqua Marcia und die Brücke über die Fossa Traiana (der Straße Ostia-Porto). ${ }^{76}$ Man regulierte den Anio und sorgte für die Aqua Claudia. ${ }^{77}$ Die Entwicklung des Campus Martius wurde gesetzlich geregelt. ${ }^{78}$ Dort waren freilich römische Aristokraten aktiver als der Kaiser: Acilius Glabrio Sibidius signo Spedius gründete ein neues Forum. ${ }^{79}$ Auf dem Pincio dürfte ein kaiserlicher Palast entstanden sein. ${ }^{80}$ Auf dem Forum Romanum ehrte man Honorius jeweils nach den wichtigen Erfolgen Stilichos: Eine Quadriga erinnerte an den Sieg über Gildo im Jahre $398,{ }^{81}$ eine Statue des Honorius an den Sieg über die Goten 402 bei Verona und Pollentia. ${ }^{82}$ Ein möglicherweise wieder verwendeter - Ehrenbogen auf dem Marsfeld sollte einen Sieg über die Goten verewigen. ${ }^{83}$ Die von Theodosius begonnene Paulus-Basilika wurde vollendet. ${ }^{84}$ Bei St. Peter ließ Honorius um 400 ein Mausoleum errichten. In ihm wurden seine beiden Frauen Maria (407 verstorben) und Thermantia (415 verstorben) - beides Töchter Stilichos und Serenas - beigesetzt, dann vermutlich auch Honorius selbst sowie nach ihm wohl Valentinian III. ${ }^{85}$ Die Stadtmauern wurden in den Jahren 401-402 unter Stilicho verstärkt. Der Stadtpräfekt Flavius Macrobius Longinianus führte die Arbeiten aus. ${ }^{86}$

In Rom weilte damals auch Serena. Sie setzte sich dafür ein, dass die vornehme Römerin Melania und ihr Gemahl Pinianus Ideale von einem streng christlichen Leben der Askese und caritas verwirklichen konnten und zu diesem Zwecke ihre reichen Güter gegen den Willen ihrer Familie auflösen durften. Sie erwirkte durch Honorius ein Dekret: Die Statthalter der Provinzen, in denen Melania Güter besaß, wurden angewiesen, diese zu einem angemessenen Preis

76 Pompejus-Theater: CIL VI.1191 = ILS 793 (Codex Einsidlensis 326); Platner/Ashby 1965, 79 (Basilica Iulia). 517 (Pompejus-Theater); Aqua Marcia: Steinby 1993 (Bd. 1), 68 (D. Cattalini). Straße Ostia-Porto, Inschrift: Ensoli/La Rocca 2000, 470 f.

77 ILS 795 = CIL IX.4051; Steinby 1993 (Bd. 1), 63 f. s. v. Aqua Claudia (Z. Mari).

78 Cod. Theod. 14.14 (7.?4.397); Steinby 1993 (Bd. 1), 224 (T. P. Wiseman).

79 Niquet 2000, 253-259.

80 Steinby 1995 (Bd. 2), 70 s. v. Horti Lucullani (H. Broise/V. Jolivet).

81 CIL VI.1187 = 31256 (vgl. 36888; p. 4333-4334) $=3225^{*}=\mathrm{X} .1715=$ ILS 794, 8951; Bauer 1996, 39-41, 404 f.; Ruck 2007, 261, 297 Nr. 100.

82 CIL VI.31987 = ILS 799; Bauer 1996, 20 f. - Statuen für Honorius ließen insbesondere Stadtpräfekten aufstellen, in diesem Falle Pisidius Romulus. Zur Tätigkeit der Stadtpräfekten: Chastagnol 1962, 246 ff. Zu den Statuenehrungen vgl. auch Ruck 2001.

83 CIL VI.1196 = ILS 798 (codex Einsidlensis 326); Platner/Ashby 1965, 33 f.; Walser 1987, 76 f.; Steinby 1993 (Bd. 1), 79 f. s. v. Arcus Arcadii, Honorii et Theodosii (C. Lega); Mayer 2002, $205 \mathrm{f}$.

84 ICUR, NS II 4780; ILCV 1761a.

85 ILS 800; Paulus Diaconus, Historia Romana 13.7; vgl. Lib. pontif. I. 455, 464. D. Gaborit-Chopin, in: Ensoli/La Rocca 2000, 468 f.; Johnson 2009, 167-179.

86 Steinby 1996 (Bd. 3), 290-299 s. v. Muri Aureliani (G. Pisani Sartorio). 
zu verkaufen. ${ }^{87}$ Unter den heidnischen Senatoren löste dieses Vorgehen große Verbitterung aus. Diese dürfte umso größer gewesen sein, als sich seit 404 eine deutliche Bevorzugung christlicher Amtsträger in der Personalpolitik des Kaisers nachweisen lässt. Honorius war auch im Winter 407 in Rom. ${ }^{88}$ Seine zweite Heirat, mit Thermantia, dürfte 408 in Rom geschlossen worden sein. Stilicho war während des Winters 407/08 gleichfalls anwesend. Für das Jahr 408 wurden Anicius Auchenius Bassus und der wohl aus dem Osten stammende Flavius Philippus zu Konsuln ernannt. Honorius war offenbar in Rom, als ihm die ersten Gerüchte vom Tode des Arcadius mitgeteilt wurden. ${ }^{89}$

\section{Zuspitzung der Krise - Honorius und der Fall Roms ${ }^{90}$}

Das Verhältnis zum Osten und die Nachfolge des Kaisers in Konstantinopel bezeichnen nur eines der zahlreichen Problemfelder jener Epoche. Honorius konnte dies nicht gleichgültig sein. Es war unmöglich, auf die drängenden Fragen keine Antworten zu geben. Honorius hätte seine Macht sofort verloren. So ist er denn als Akteur in den Darstellungen des krisenhaften Prozesses bis hin zum Fall Roms unentbehrlich. Nach allem, was wir wissen, gründet sein Einfluss primär auf seiner Stellung als Kaiser. Diese setzte er ein - ein Einsatz der zum Untergang Stilichos und zur Einnahme Roms durch Alarich führte, aber die Macht Roms dennoch sicherte und ebenso sein Kaisertum. Gewiss, hier wie auch bei allen anderen Schwierigkeiten, insbesondere dem Umgang mit den Goten, konnte Honorius nur handeln, weil er sich immer wieder auf seinen magister militum Flavius Stilicho abstützte, den Sohn einer Römerin und eines Vandalen, der durch die Heirat mit der Nichte des Theodosius eng mit der kaiserlichen Dynastie verbunden war. Theodosius hatte Stilicho kurz vor seinem Tod bei einem Aufenthalt in Rom die Fürsorge für Honorius und die westliche Reichshälfte übertragen. ${ }^{91}$

Im Osten erhielten Militärs keine solche den Kaiser geradezu überschattende Stellung. Doch die sicherheitspolitischen Bedrohungen im Westen waren größer. Dabei konnten die germanischen Heermeister den Kaisern und dem Reich ihrerseits gefährlich werden. Mit dem Franken Arbogast hatte man dies erlebt.

87 Vita Melaniae iunioris 12 (SC 90, p. 152). Vgl. Janssen 2004, 157-165.

88 Zos. 5.27.2. In Rom werden Cod. Theod. 1.20.1 und 14.4 .8 erlassen (vgl. weiter Anm. 74).

89 Zos. 5.31.1.

90 Chronologische Übersicht bieten: Jaffé 1885, 45 f.; Seeck 1919, 313 f. Weiter: Demougeot 1951; Matthews 1990, 270-306; Wolfram 1990, 158-166; Demandt 2007, 174-179; Heather 2007; Kulikowski 2009; Moorhead/Stuttart 2010; Meier/Patzold 2010 .

91 Zos. 4.59.1; vgl. Oros., hist. 7.37.1. 
Arbogast mangelte es an Loyalität zu Valentinian II. Es hieß gar, er habe den jungen Kaiser ermordet. Sicher ist, dass er wenige Jahre später die Usurpation des Eugenius unterstützte. Stilicho hatte ein engeres Verhältnis zur kaiserlichen Familie, denn er war ihr auch durch Heirat verbunden: Etwa 384 hatte er Serena zur Frau bekommen, die Tochter des ebenfalls Honorius heißenden Bruders des Theodosius (sowie vielleicht der Maria). Serena war einst nach dem Tode ihres Vaters von Theodosius I. adoptiert worden. 398 wurde dann Honorius mit der Tochter des Stilicho und der Serena, der wohl nur etwa zehnjährigen Maria, verheiratet. Nach deren frühem Tod ehelichte Honorius 408 deren Schwester Thermantia. Beide sollen als Jungfrauen gestorben sein. ${ }^{92}$ Seinen Sohn Eucherius verlobte Stilicho mit Galla Placidia, der Halbschwester des Honorius. 400 und 405 bekleidete Stilicho den Konsulat. Zu Senat und Aristokratie versuchte er gute Beziehungen zu pflegen. Im Osten sah man ihn mit kritischen Augen, ja erklärte ihn zum Reichsfeind. Östliche und westliche Interessen prallten vor allem in Illyricum, in Afrika, in der Frage des Umganges mit den Barbaren sowie in konfessionellen Auseinandersetzungen aufeinander.

Die schwierigste Aufgabe Stilichos bildeten die Auseinandersetzungen mit den Germanen. Dabei erzielte Stilicho lange geradezu erstaunliche Erfolge. Ähnlich erfolgreich, wie er mit dem vom Osten unterstützten Aufstand des Gildo in Afrika, der Kornkammer Roms, fertig geworden war, gelang es ihm, auf das Eindringen Alarichs nach Italien 401/02 eine Antwort zu geben. Stilicho entsetzte das belagerte Mailand und besiegte die Goten 402 bei Verona und Pollentia. Goten und Römer waren allerdings keineswegs einfach nur Feinde. Die Goten hatten vielmehr seit 382 den Status von Foederaten, und Römer bedienten sich ihrer im Osten wie im Westen. Der Begriff foederati findet sich dann erstmals in einem in Ravenna erlassenen Gesetz vom 17. April 406. ${ }^{93}$ Zuvor hatte Stilicho Alarich benutzt, um Illyricum wieder zu gewinnen. Honorius ernannte den Goten auf die Veranlassung Stilichos hin zum magister militum. ${ }^{94}$ Beinahe wäre es zum Krieg mit Arcadius gekommen.

Doch dann entbrannten die Zielkonflikte zwischen Goten und Römern aufs Neue. Weder konnte man sich über die Gebiete der Niederlassung, den Status ihrer Anführer noch die finanziellen Forderungen einigen. 407 marschierte Alarich erneut in Richtung Italien und verlangte 4000 Pfund Gold dafür, dass er von einem Feldzug absehe. Alarich wusste, wie schwierig die Lage der Römer war. Ein Jahr zuvor war der 405 aus Pannonien eingebrochene Radagais mit

92 Olymp., fr. 1.2 Blockley; Chronica Minora 2 (MGH AA 11). p. 69; Jord., Get. 154. Hochzeitskameo für Maria und Honorius: Meischner 1993; vgl. auch Spier 2007, 131 (Nr. 717).

93 Cod. Theod. 7.13.16.

94 Soz., h.e. 7.25 .3 ; 9.4.2. 
großer Anstrengung von Stilicho bei Faesulae mit Hilfe von Hunnen und Goten besiegt worden.

Im gleichen Jahr 406 überschritten mehrere germanische Völker den Rhein und brachen in Gallien ein. 407 wurde der einfache Soldat Constantinus in Britannien zum Augustus (Constantinus III.) proklamiert. Er ging nach Gallien, wo er in Lyon und später in Arles Residenz nahm. Aufstände in der Aremorica und Erhebungen der Bagauden begleiteten den Auflösungsprozess des Imperiums. Noch konnten Stilicho und Honorius sich halten. Doch im Jahre 408 kam es zum Bruch zwischen den beiden und zum Ende Stilichos. Die Vorgänge lassen sich im Einzelnen nicht klar rekonstruieren, und dies ist zu unterstreichen. Das Bild, das ich im Folgenden skizziere, vermag allein zu zeigen, dass Honorius und sein Hof in den verschiedenen Quellenzeugnissen, auf welche man sich bei einer Analyse zu stützen hat, ebenso präsent sind wie - nebst weiteren Kräften und bedingenden Faktoren (wie das Verhalten des Ostens oder die Versorgung Roms) - die römische Aristokratie, der Senat und die Kommunikation zwischen diesen Mächten. Keinesfalls lässt es sich rechtfertigen, Honorius als zu vernachlässigende Größe beiseite zu schieben oder primär in Alarich und den Goten die wichtigsten Akteure zu sehen. Wie bereits erwähnt hatte Alarich 4000 Pfund Gold als Ablasszahlung verlangt. Stilicho überzeugte Honorius und den römischen Senat, diese Summe zu zahlen. ${ }^{95}$ Er hoffte damit, Alarich gegen den Usurpator Constantinus III. zu gewinnen. Offenbar nur einer unter den Senatoren protestierte, Lampadius, von dem Zosimos die Worte überliefert: Non est iste pax, sed pactio servitutis - „was,“ wie Zosimos weiterfährt, „besagt, dass das Abkommen eher Versklavung als Friede beinhalte. "96 Aus Furcht vor Vergeltung durch Stilicho musste dieser vermutlich heidnische Aristokrat, der wohl auch ein naher Verwandter des Prätorianerpräfekten Flavius Manlius Theodorus war, in eine Kirche fliehen.

Nicht nur das Vorgehen gegenüber Alarich war damals strittig. In weiteren Fragen war man sich uneinig. Wie wollte man die Interessen im Illyricum wahrnehmen? Wie sollte man sich überhaupt gegenüber dem Osten verhalten? Als der Ostkaiser Arcadius starb, wuchs der Handlungs- und Entscheidungsdruck. Honorius hörte erstmals vom Tode seines Bruders in Rom. Offizielle Mitteilungen standen aber offenbar aus. In Ravenna bestätigten sich die Gerüchte. Honorius traf Stilicho, dieser sollte in den Osten reisen. In dieser Situation kam es zu Meutereien. Verdächtigungen gegenüber Stilicho entstanden. In Pavia verlor unter anderem der praefectus praetorio Italiae Flavius Macrobius Longinianus als Anhänger Stilichos sein Leben. Honorius ließ sich offenbar durch seinen magister officiorum Olympius davon überzeugen, Stilicho plane, den Kaiserthron für sich selbst und seinen Sohn Eucherius zu übernehmen. Auf

95 Olymp., fr. 7.2 Blockley.

96 Zos. 5.29.9. 
Grund eines schriftlichen Befehles wurde Stilicho durch Heraclianus schließlich am 22. August 408 in Ravenna enthauptet. Eucherius wurde auf Befehl des Honorius in Rom hingerichtet. Serena verlor ihr Leben nach einem Prozess, den der Senat in Rom gegen sie führte. ${ }^{97}$ Thermantia, die Honorius zu ihrer Mutter nach Rom zurückgeschickt hatte, lebte noch bis 415 .

Nach dem Tode Stilichos und seiner Familie - einer Katastrophe, welche die Stellung des Honorius schwerstens erschütterte - wurde das Problem des Umganges mit Alarich nur noch dringender und schlimmer. Es kam zu Ausschreitungen gegen germanische Soldaten, und Alarichs Anstrengungen, einen sicheren Platz im Imperium zu gewinnen, wurden noch energischer. Zahlreiche germanische Soldaten desertierten und schlossen sich Alarich in Noricum an. ${ }^{98}$ Alarich verlangte erneut Gold. Als seine Forderungen nicht erfüllt wurden, zog er Richtung Rom und belagerte die Stadt erstmals im Winter 408/09. Bald gaben die Römer auf und nahmen Verhandlungen mit Alarich auf. Der Senat erklärte sich bereit, eine Gesandtschaft nach Ravenna zu schicken. Diese brachte es denn auch fertig, dass Olympius den Römern und Alarich entgegenkam und Alarich zu Verhandlungen nach Rimini einlud. Sie wurden vom Prätorianerpräfekt Iovius, einem Konkurrenten des bald danach in Ungnade fallenden Olympius geführt, und scheiterten: Der Kaiser mit seinem Schreiben lehnte es strikt ab, dass Alarich zum magister militum ernannt würde. ${ }^{99}$ Alarich zog wieder gegen Rom und erhob dort einen Usurpator, den Stadtpräfekten Attalus. Dafür erhielt er das von ihm begehrte Heermeisteramt. Attalus zählte zu den Anhängern der traditionellen Religion. Hinter ihm stand offenbar der Senat in seiner Gesamtheit. Die Anicii lehnten ihn allerdings ab. ${ }^{100}$ Iovius ging zu Attalus über - um ihn später dann doch wieder zu verlassen. ${ }^{101}$ Die Mehrheit unter der Aristokratie dürfte Attalus rasch verloren haben, als er sich nach seiner Erhebung durch einen arianischen Bischof der Goten taufen ließ. ${ }^{102}$ Attalus wurde von Honorius die Bereitschaft zur Anerkennung und Teilung der Herrschaft übermittelt, aber vom Usurpator nicht angenommen. Anmaßend verlangte Attalus, Honorius solle den Thron aufgeben und sich ins Exil auf eine Insel begeben. ${ }^{103}$

In diesem schwierigen Moment kam Hilfe aus dem Osten. 4000 Soldaten landeten in Ravenna und ermöglichten das weitere sichere Verbleiben des Kaisers in der Stadt und in Italien. ${ }^{104}$ Gleichzeitig versuchten Honorius und

97 Vgl. Demandt/Brummer 1977.

98 Zos. 35.5-6.

99 Zos. 5.48 .

100 Zos. 6.7.4; 6.9.3.

101 Vgl. Lütkenhaus 1998, 24-29.

102 Soz., h.e. 9.9.1. Vgl. auch Philost., h.e. 12.3; Zos. 6.7.3 ff.

103 Olymp., fr. 10.1 Blockley (=Soz. h.e. 9.8.5). 14; vgl. Zos. 6.8.1.

104 Zos. 6.8.2. 
Konstantinopel die Kontakte des Usurpators auf Italien zu beschränken. ${ }^{105} \mathrm{Da}$ es Attalus nicht gelang, die Versorgung Roms zu verbessern, verlor er rasch die Zustimmung in Rom. So gab Alarich selbst Attalus auf, verhandelte weiter mit Ravenna und setzte den Usurpator ab. Diadem und Purpur schickte er zu Honorius. ${ }^{106}$ Die Verhandlungen mit Honorius kamen nicht voran. Dafür wurde Alarich vom gotischen General Sarus angegriffen. Alarich wandte sich enttäuscht wieder Rom zu und ließ die Stadt im August 410 einnehmen und plündern. ${ }^{107}$ Alarich holte sich die Mittel für seine Goten, respektierte das Apostelgrab und verließ nach drei Tagen die Stadt. Danach wandte er sich nach Süden und scheiterte beim Versuch, nach Sizilien und vielleicht nach Afrika zu gelangen. Wenig später erlag er einem tödlichen Fieber in Cosentia und wurde im Fluss Busento bestattet. Unter seinem Nachfolger Athaulf zogen die Westgoten nach Gallien. Athaulf heiratete Galla Placidia, die bei der Plünderung Roms von den Goten als Geisel genommen worden war. Orosius berichtet von Athaulf:

Wie man oft gehört hat und wie es durch die letzte Stunde seines Lebens erwiesen ist, hat er, ein ganz eifriger Anhänger des Friedens, es vorgezogen, treu dem Kaiser Honorius Kriegsdienst zu leisten ... Nach Auslöschung des römischen Namens habe er vor allem mit glühendem Eifer darnach getrachtet, den ganzen römischen Reichsboden zu einem Reich der Goten zu machen, damit - volkstümlich gesprochen - Gotia heiße und sei, was einst Romania gewesen sei und jetzt Athaulf das werde, was einst Caesar Augustus gewesen sei. Nachdem er aber durch unablässige Erfahrung zur Erkenntnis gekommen sei, dass weder die Goten wegen ihrer zügellosen Wildheit auf irgendeine Weise Gesetzen gehorchen könnten, noch die Gesetze des Staates, ohne die ein Staat kein Staat sei, verboten werden könnten, habe er vorgezogen, sich durch die völlige Wiederherstellung und Mehrung des römischen Namens mit Hilfe der gotischen Streitkräfte Ruhm zu erwerben. ${ }^{108}$

Trotz der Katastrophe orientierten sich politische Hoffnungen für die Gestaltung der Zukunft weiterhin am römischen Ordnungsmodell. Nach wie vor schaute man achtungsvoll auf Kaiser Honorius und Rom.

\section{Die Erholung Roms}

Rasch wurde die Katastrophe relativiert. Es sei, so Augustin, das dritte Mal, dass Rom brenne. ${ }^{109}$ Doch vielleicht gehe Rom nicht zugrunde, vielleicht sei es nur gezüchtigt worden, bestraft, und nicht vernichtet. ${ }^{110}$ Orosius vermittelt den

105 Vgl. Cod. Theod. 7.16.2 (24.4.410). Vgl. dazu Millar 2004, 567-689, 569 f.

106 Zos. 6.12.2.

107 Soz., h.e. 9.9.2-4; Philost., h.e. 12.3. Vgl. Zos. 6.13.2.

108 Oros., hist. 7.43.3-6, deutsch: A. Lippold; vgl. Olymp., fr. 26.1 Blockley.

109 So Aug., serm. 296.7; vgl. Fuhrer 69-71 in diesem Band. 
Eindruck, man sehe eigentlich schon fast nichts mehr von den Zerstörungen, obschon die vom Brand her rührenden Trümmer und die noch frische Erinnerung es unmöglich machen würden, die Ereignisse zu leugnen. ${ }^{111}$ Rutilius Namatianus erwähnt gleichfalls Zerstörungen, aber nicht in Rom, sondern in Italien. ${ }^{112}$ Weil die Wege nicht mehr funktionierten, wählte er denn das Schiff für seine Rückreise aus der geliebten Hauptstadt, in der er als Stadtpräfekt amtiert hatte, zurück in seine Heimat Gallien. Olympiodor und Philostorgius halten fest, dass nach der Einnahme Roms durch die Goten die Stadt sich erholt und die Bevölkerung wieder zugenommen habe. ${ }^{113}$ Gemäss Philostorgius besuchte Honorius die Stadt und förderte diesen Prozess. Olympiodor verknüpft seine Angaben mit der Stadtpräfektur des Albinus 414. 14000 Kinder würden geboren, das Getreide aus Afrika reiche nicht mehr. Die Saturnalien des Macrobius bieten das Bild einer römischen Aristokratie, welche nach wie vor die traditionelle Kultur pflegen konnte. Prokop wiederum sah aber noch immer nicht wieder hergestellte Ruinen und erwähnt das verfallene Haus des Sallust. Italien sei noch immer menschenarm. ${ }^{114}$

Am 23. Januar 411 feierte Honorius, wie Marcellinus Comes verzeichnet, seine Vicennalia in Rom. ${ }^{115}$ Diese Angabe bereitet allerdings Schwierigkeiten, gehören doch die Vicennalia erst in das darauffolgende Jahr, in dem Honorius auch - zum neunten $\mathrm{Mal}$ - den Konsulat ausübte. 411 gab es keinen westlichen Konsul; der Ostkaiser Theodosius, der seine Decennalien (eigentlich auch erst 412) feierte, übte diese Funktion alleine aus. Ein in Ravenna erlassenes Gesetz von 411 (die Datierung ist aber umstritten) erwähnt Verwüstungen in Italien und Rom, die offenbar Menschen veranlasst haben, weg zu ziehen. ${ }^{116}$ Am 28. Nov. 411 erhielt der Stadtpräfekt von Rom, Bonosianus, ein Gesetz, in dem es um den Schutz alter Bauten ging. ${ }^{117}$ Gesetze, welche sich mit Rom in diesen Jahren befassen, betreffen Regelungen der Korporationen. Bereits am 25. September 410 (Einnahme Roms am 24. August) war eine Regelung für die Curien erlassen worden: In die Korporation von Klerikern im Dienste des Kaisers dürfe sich niemand einschleichen. ${ }^{118}$ Weitere Gesetze betreffen die annona, ${ }^{119}$ die Salutationen ${ }^{120}$ und die Officialen. ${ }^{121}$ Am 12. Dezember 416 wurde das Tragen

110 Aug., serm. 81.9.

111 Oros., hist. 7.40.1.

112 Rut. Nam. 39-42.

113 Olymp., fr. 25 Blockley; Philost., h.e. 12.5.

114 Prok., Vand. 1.2.24.

115 Chronica Minora 2 (MGH AA 11). p. 70. Vgl. Orlandi 2004, 80.

116 Cod. Theod. 7.13.20.

117 Cod. Theod. 15.1.48.

118 Cod. Theod. 14.1.6 an den Stadtpräfekten Bonosianus.

119 Cod. Theod. 13.5.38 (17.9.414) an den Stadtpräfekten Albinus.

120 Cod. Theod. 6.18.1 (15.10.412) an den Stadtpräfekten Epifanius. 
germanischer Tracht in Rom verboten, eine Massnahme, die offenbar für den zivilen Charakter der Hauptstadt sorgen sollte. ${ }^{122}$ Der Erlass richtet sich an den Stadtpräfekten Probianus, in dem man wohl jenen vicarius urbis Romae sehen darf, der sich auf einem Diptychon sowohl in Chlamys als auch in Toga abbilden ließ. Auf dem Amtstintenfass sind die Porträtbüsten der beiden regierenden Kaiser zu sehen. ${ }^{123}$ Im Jahre 411 gelang die Niederschlagung des Aufstandes in Gallien. Der neue General des Honorius, Flavius Constantius, erwies sich als höchst effizient. Weit im Westen gelang die Ansiedlung der Goten. Athaulf, der nach der Ermordung Alarichs an dessen Stelle getreten war, heiratete 414 Galla Placidia und strebte die Herstellung eines neuen Rom zusammen mit seinen wilden Goten an. ${ }^{124}$

Honorius verdankte seine Erfolge nach 410 wesentlich dem aus Naissus stammenden neuen Heermeister Flavius Constantius. Dieser erhielt denn auch rasch die höchsten Auszeichnungen. 417 heiratete er Galla Placidia und feierte sein zweites Consulat. Auf dem später in den Domschatz von Halberstadt gelangten Diptychon steht der spätere Mitregent des Honorius und Augustus Constantius einmal in triumphaler Trabea und einmal in Chlamys jeweils unterhalb eines Tribunals, in dem die kaiserliche Familie zwischen den Stadtgöttinnen von Rom und Konstantinopel abgebildet wird: Dabei sitzt der kleinere Ostkaiser Theodosius II. vom Betrachter her gesehen rechts neben dem größeren Honorius - hinter den beiden Herrschern ist wohl Galla Placidia dargestellt. ${ }^{125}$ Der Einfluss des Constantius auf die Politik war groß, wie sich noch Sidonius Apollinaris gerne erinnerte. ${ }^{126} \mathrm{Im}$ Osten lehnte man ihn ab; Theodosius II. versagte ihm die Anerkennung, als Honorius ihn 421 zum Augustus proklamierte. ${ }^{127}$ Honorius feierte seine Erfolge mit einem weiteren Triumph in Rom. Am 3. Mai 416 oder 418 führte er dabei den mehrmals erhobenen römischen Usurpator Attalus vor, ließ ihm zwei Finger der linken Hand abschneiden und verbannte ihn auf die Insel Lipara, ähnlich wie es der Usurpator ihm einst angedroht hatte. ${ }^{128}$ Sowohl Sozomenos als auch Orosius wussten die

121 Cod. Theod. 8.7.20 (25.7.415) an den Stadtpräfekten Gracchus.

122 Cod. Theod. 14.10.4. Vgl. Lejdegård 2002, 69-73.

123 Delbrueck 1929, 250-256 (Nr. 65).

124 Oros., hist. 7.43; vgl. oben Ende Abschnitt 6.

125 Delbrueck 1929, 87-93 (Nr. 2); Olovsdotter 2005, 20-23.

126 Sidon., c. $7.210-211$.

127 Olymp., fr. 33 Blockley; Philost., h.e. 12.12.

128 Prosp. Tiro s. a. $417=$ Chronica minora 1 (MGH AA 9). p. 468: Honorius Romam cum triumpho ingreditur praeeunte currum eius Attalo, quem Liparae vivere exulem iussit. Attalus war um die Jahreswende 413/14 von den Westgoten in Gallien zum Kaiser erhoben worden. 415/416 ließen sie ihn in Gallien zurück, und er fiel in die Gewalt des Honorius: Paul., euch. 292-302; Prosp. Tiro s. a. 414 und $415=$ Chronica minora 1 (MGH AA 9). p. 467. Vgl. Philost., h.e. 12.4-5 = Olymp., fr. 26.2 Blockley (Verbannung und Abschlagen der zwei Finger). Vgl. Lejdegård 2002, 121-156. 
Erfolge des Honorius gegen die verschiedenen Usurpatoren ausführlich zu würdigen. ${ }^{129}$ In jenen Jahren erfolgte vermutlich auch eine Renovation des Colosseums. ${ }^{130}$

Der Stadtpräfekt Aurelius Anicius Symmachus (418-420) bezeichnete auf einer Statuenbasis im Pompejustheater Honorius als Romani orbis libertatisque custos, pius Augustus und invictus princeps. ${ }^{131}$ Auf der Statuenbasis im Trajansforum für den Stadtpräfekten Petronius Maximus (420-421) wurden Honorius, Constantius und Theodosius II. als invictissimi principes und censores, remuneratoresque virtutum in Erinnerung behalten. ${ }^{132}$ Folgenreich war, dass der Kaiser sich als Appellationsinstanz in kirchlichen Streitigkeiten etablierte, so in den Auseinandersetzungen mit den Pelagianern und im Donatistenstreit. In einer Auseinandersetzung um die Oberhoheit des Papstes im Illyricum nahm er für die römische Autorität Stellung und schrieb an Theodosius II. am 14. Juli 421 Worte, die höchst aufschlussreich für das Verständnis seines Kaisertums und dessen Verhältnis zu Rom und zum römischen Bischof sind:

Besondere Sorge und Eifer müssen wir solchen Petitionen widmen, in welchen Wünsche des heiligen apostolischen Stuhls enthalten sind. Denn da unser Kaisertum stets durch göttliche Gnade gelenkt wird, so ist ohne Zweifel von uns besondere Verehrung der Kirche jener Stadt darzubringen, von der wir den römischen Principat empfangen haben und wo der Ursprung des Priestertums ist. ${ }^{133}$

Wiederholt vermittelte Honorius bei Papstschismen - seine Interventionen, die im Kern Ansätze des Kirchenvaters Cyprian aufgriffen, lieferten zugleich eine erste Papstwahlanordnung in einer langen Reihe künftiger Regulierungen mit ähnlichen Absichten: Als Papst Zosimus, der Nachfolger von Innocenz I. (402417), nach einem nur einjährigen Pontifikat verstarb, kam es zu einer Doppelwahl und erheblichen Unruhen in Rom, denen der Stadtpräfekt Aurelius Anicius Symmachus nicht wirklich Herr wurde. Bonifatius fand in der römischen Aristokratie mehr Zustimmung. Er erhielt Oberhand und auch die Unterstützung durch Galla Placidia sowie Honorius und den von diesem konsultierten Senat, obschon dieser zunächst wie auch der Stadtpräfekt Eulalius vorgezogen und Bonifatius gar aus Rom ausgewiesen hatte. ${ }^{134}$ Die Sorge vor einer Wiederholung schismatischer Wirren bewegte Bonifatius zur Erwirkung eines kaiserlichen Reskriptes, das für alle Zukunft Amtsjägerei bei Papstwahlen verbieten wollte. ${ }^{135}$ Während des Schismas waren unter anderem auch Sicher-

129 Soz., h.e. 9.11.16; Oros., hist. 7.42.

$130 \mathrm{Vgl}$. Orlandi 2004, Inschrift 7, v. a. $82 \mathrm{f}$.

131 CIL VI.1193; Chastagnol 1962, 280.

132 CIL VI.1749 = ILS 809; Chastagnol 1962, $281 \mathrm{f}$.

133 Silva-Tarouca 1937, $41 \mathrm{f}$. (Collectio Thessalonicensis 15); Caspar 1930, 375.

134 Caspar 1930, 360-365; Pietri 1976, 452-460; Sivan 2011, 72-79; Thier 2011, 141 145.

135 Avell. Nr. 37; vgl. Caspar 1930, 365. 
heitskräfte der Korporationen eingesetzt worden. ${ }^{136}$ Honorius kümmerte sich in jenen Jahren mit einer Reihe von Gesetzen um sie, wobei offenkundig aber wirtschaftliche Aspekte wichtiger waren als die Bedeutung bestimmter Korporationen für das Stellen von Sicherheitskräften. ${ }^{137}$ In der Frage des Verhaltens gegenüber den Anhängern des Pelagius fügte sich der römische Bischof dem kaiserlichen Entscheid, diese auszuweisen und ihr Vermögen zu konfiszieren. ${ }^{138}$

Von erheblicher Wichtigkeit sind sodann die Regelungen für die Standesgerichtsbarkeit der Senatoren im Jahre 423. Senat und Senatorenstand hatten in jenen Jahren offensichtlich an Bedeutung gewonnen, wie in den vorangegangenen Ausführungen immer wieder deutlich geworden ist. In diesem Zusammenhang kann auch noch ergänzt werden, dass damals Reparaturen an der Curie ausgeführt wurden. ${ }^{139}$ Honorius regelte nun die Standesgerichtsbarkeit neu. Die diesbezügliche Gesetzgebung steht in einer langen Tradition und sollte den Adel vor missbräuchlichen Anklagen schützen. Sie sorgte einerseits für die Rechte und Privilegien des Senatorenstandes und schützte andererseits den Kaiser vor hochverräterischem Vorgehen. Sie ist ein deutlicher Ausdruck des Zusammengehörens und Angewiesenseins von Adel und Kaiser. ${ }^{140}$ Honorius, wie alle Kaiser, war auch darauf bedacht, dass seine Erlasse in Rom wahrgenommen wurden. So wurden noch immer bestimmte Gesetze auf Bronzetafeln im Trajansforum aufgestellt. ${ }^{141} 422$ feierte Honorius die Vicennalien allerdings nicht in Rom, sondern in Ravenna. In diesem Jahr übte er das Amt eines Konsuls zusammen mit Theodosius aus. Sein Verhältnis zum Osten dürfte indes einmal mehr gespannt gewesen sein. Vor allem zeichnete sich ein Streit mit seiner energischen Schwester Galla Placidia ab, obschon er sie angeblich einmal so geliebt hatte, dass sogar Skandalgeschichten von unsittlichen Küssen zwischen den beiden in Umlauf gebracht wurden. In Ravenna kam es zu Straßenkämpfen. Galla Placidia wurde verbannt und fand am Hofe in Konstantinopel Unterstützung. ${ }^{142}$ Die Fortsetzung der dynastischen Politik lag fortan in ihrer Hand. Wie ihr Bruder - nur tatkräftiger - suchte sie das Zusammengehen mit der Kirche, wie er suchte sie nach geeigneten Heermeistern und setzte in ihrer Gesetzgebung auf den Ausgleich mit der Aristokratie.

136 Vgl. Chastagnol 1960, $260 \mathrm{f}$.

137 Cod. Theod. 14.2 .4 (29.3.412); 14.4 .10 (29.7.419) (vgl. Steinby 1995 [Bd. 2], 346 f. [L. Chioffi] - Gründung des ordo der pecuarii mit dem corpus suariorum).

138 Wermelinger 1975, 196-209.

139 Bartoli 1963, 43 f.; Fraschetti 1999b, $221 \mathrm{f}$.

140 Cod. Theod. 1.6.11; 2.1.12; 4.10.2; 9.6.4. Vgl. Coster 1935, v.a. 7 f.; Giglio 1990, 202-206; Vincenti 1992, v. a. 67-76.

141 Cod. Theod. 10.10 .31 (25.8.422); 11.20 .4 (19.5.423).

142 Olymp., fr. 38 Blockley. Vgl. Sivan 2011, 78 f. 
Im August 423 starb Honorius - wie sein Vater an Wassersucht. ${ }^{143}$ Es würde sich gut in seine Selbstdarstellung fügen, hätte er eine Bestattung im Mausoleum der Familie bei St. Peter angeordnet. St. Peter spielte bei seinem Triumph in Rom 404 und 416/17 eine wichtige Rolle. Es war ein Symbol des Glaubens und der Treue zum christlichen Rom. Honorius hatte ihm insbesondere bei seinem Triumph im Jahre 404 eindrucksvoll Referenz erwiesen. St. Peter, so hieß es, sei sogar von den Goten während der Plünderung Roms respektiert worden: Orosius überliefert die wundersame Geschichte einer Prozession zur Apostelkirche während der Plünderung Roms: Römer - Altgläubige wie Christen - und Barbaren, insbesondere aber auch Jungfrauen, seien Hymnen singend nach St. Peter gezogen, goldene und silberne Geräte seien mitgetragen worden, die Goten hätten für den Geleitschutz gesorgt. ${ }^{144}$

Das Grab des Honorius wurde zwar in den kommenden Jahrhunderten vergessen. Honorius galt im Vergleich zu Konstantin oder Theodosius als weniger wichtig. Immerhin wurde von Paulus Diaconus festgehalten, Honorius sei in der Nähe Roms gestorben und in einem Mausoleum bei St. Peter bestattet worden. ${ }^{145}$ Offenbar handelt es sich dabei um einen Anbau von St. Peter, welcher Petronilla geweiht war. Petronilla wurde seit dem 4. Jahrhundert als Stadtpatronin Roms verehrt. Das Mausoleum wurde erst in der Neuzeit geöffnet. 1544, gut eineinhalb Jahrzehnte nach einem weiteren Sacco di Roma, zogen die mit kostbaren Beigaben ausgestatteten Gräber Aufsehen auf sich. Die detaillierteste Schilderung der Funde bieten Briefe des Zürcher Reformators Heinrich Bullinger. In einem seiner Schreiben gibt er der Angst Ausdruck, der Untergang Roms zur Zeit des Honorius könne sich in der Gegenwart wiederholen - offenbar dachte er an die Bedrohung, die von den Türken ausging. ${ }^{146}$

143 Wohl am 15.8. Olymp., fr. 39 Blockley; Philost., h.e. 12.13; Socr., h.e. 7.22.20. Bei dieser Krankheit - wohl Diabetes - kannte man keine wirkungsvolle Therapie, vgl. Cael. Aur., tard. pass. 96-155.

144 Oros., hist. 7.39.3-10.

145 Paulus Diaconus, Historia Romana 13.7: ... apud urbem Romam exemptus est corpusque eius iuxta beati Petri apostoli martyrium in mausoleo sepultum est. Vgl. Lib. pontif. I. 455, 464.

146 Heinrich Bullinger Werke, Zweite Abteilung, Briefwechsel, Bd. 14, Briefe des Jahres 1544 , bearbeitet von Reinhard Bodenmann/Rainer Henrich/Alexandra Kess/Judith Steiniger, Zürich 2010, 8 (Einleitung), Brief Nr. 1892, S. 194, 56-59 (Bullinger an Ambrosius Blarer 11.4. 1544): „Die nüwe zytung von Rom sind seltzam; ist neisswas dran, so möcht wol ettwas spans daruss kommen. Quid, si tempora redirent Honorii, ut nunc occidentale imperium prorsus dilaberetur, quod sub Honorio inclinare et laborare coepit?". Die ausführliche Beschreibung der Funde: Vadianische Briefsammlung, Bd. 6, 1. Hälfte, 1541-1545, hrsg. von Emil Arbenz und Hermann Wartmann, St. Gallen 1906, $303-$ 307 (Brief Bullingers an Vadian 19.4.1544), 307 f. (Beilage), Nr. 1338. Vgl. D. Gaborit-Chopin, in: Ensoli/La Rocca 2000, 468 f.; Johnson 2009, 167-179. 
Mehr als je bewegten die Menschen seiner Zeit Fragen des Glaubens und ihr Zusammenhang mit Geschichte und Politik.

Gegen 800 existierte ein positives Bild des Honorius. Beeinflusst durch christliche Autoren der Spätantike hat damals Paulus Diaconus in seiner Historia Romana festgehalten, dass Honorius seinem Vater Theodosius dem Großen nicht unähnlich gewesen sei. ${ }^{147}$ Tatsächlich gelang es Honorius, sich über den Fall Roms hinaus zu halten. Die Sorge um Rom, die Wahl einer strategisch gut gelegenen Residenz, die Zusammenarbeit mit starken Heermeistern, die Gesetzgebung, der Ausgleich mit dem Senat, die Förderung der Kirche und der Orthodoxie, die Germanen-, Gallien- und Afrikapolitik sowie die Hilfeleistungen aus dem Osten hielten ihn an der Macht. Das Bündnis des Honorius und seines Hofes mit Aristokratie und Kirche hat dabei viel geholfen. Krisen und Probleme blieben dabei ebenso wenig aus wie bei der Ausrichtung der Politik auf Erhaltung der Dynastie, die regelmäßige Publikation von Gesetzeserlassen sowie die Abstützung auf starke Heermeister. Galla Placidia benutzte nach dem Tode des Honorius die gleichen Mittel. Wirklich stabile politische Verhältnisse waren indes nicht zu schaffen. Unmittelbar nach dem Tode des Honorius zeigten sich denn die Spannungen aufs Intensivste, und nur mit Mühe konnte sich Galla Placidia mit ihrem beim Tode des Honorius vierjährigen Sohn Valentinian III. durchsetzen. Manche benutzte Strategie des Honorius und seines Hofes scheiterte oder wirkte sogar geradezu kontraproduktiv. Umso wichtiger war die Bestärkung eines Glaubens, der die sozialen und politischen Gemeinschaften in einer Epoche der Erschütterungen zusammenhielt, der Glaube an die Macht Roms und die Sieghaftigkeit seiner christlichen und angeblich einträchtig in den Reichsteilen zusammen mit Senat und Volk herrschenden Kaiser sowie der mit einem noch höheren selbsterklärenden Anspruch ausgestattete Glaube an die unerforschliche Vorsehung Gottes jenseits aller irdischen Unzulänglichkeiten. Für diesen Glauben standen mit all ihrer geradezu unglaublichen Ausstrahlungskraft Rom und die Kirche von St. Peter.

\section{Literaturverzeichnis}

Bartoli, Alfonso (1963), Curia senatus. Lo scavo e il restauro, Rom.

Bauer, Franz Alto (1996), Stadt, Platz und Denkmal in der Spätantike. Untersuchungen zur Ausstattung des öffentlichen Raums in den spätantiken Städten Rom, Konstantinopel und Ephesos, Mainz.

Benrath, Henry (Rausch, Albert H.) (1937), Die Kaiserin Galla Placidia, Berlin.

Bleckmann, Bruno (1997) „Honorius und das Ende der römischen Herrschaft in Westeuropa“, in: Historische Zeitschrift 265, 561-595.

Cameron, Alan (1970), Poetry and Propaganda at the Court of Honorius, Oxford.

147 Paulus Diaconus, Historia Romana 13.8. 
Caspar, Erich (1930-1933), Geschichte des Papsttums von den Anfängen bis zur Höhe der Weltherrschaft, 2 Bde., Tübingen.

Chastagnol, André (1960), La Préfecture urbaine à Rome sous le Bas-Empire, Paris.

Chastagnol, André (1962), Les Fastes de la Préfecture de Rome au Bas-Empire, Paris.

Coster, Charles Henry (1935), The Iudicium Quinquevirale, Cambridge (Mass.).

Deichmann, Friedrich Wilhelm (1969), Ravenna. Geschichte und Monumente, Bd. 1, Wiesbaden.

Delbrueck, Richard (1929), Die Consulardiptychen und verwandte Denkmäler, Berlin/ Leipzig.

Deliyannis, Deborah Mauskopf (2010), Ravenna in Late Antiquity, Cambridge (Mass.) u.a.

Demandt, Alexander (2007), Die Spätantike. Römische Geschichte von Diocletian bis Justinian 284-565 n. Chr., vollständig bearbeitete und erweitere Neuauflage, München.

Demandt, Alexander/Brummer, Guntram (1977), „Der Prozess gegen Serena im Jahre 408 n. Chr.", in: Historia 26, 479-502.

Demougeot, Émilienne (1951), De l'unité à la division de l'Empire romain 395-410. Essai de gouvernement impérial, Paris.

Döpp, Siegmar (1980), Zeitgeschichte in Dichtungen Claudians, Wiesbaden.

Dürrenmatt, Friedrich (1985), Romulus der Große. Eine ungeschichtliche Komödie in vier Akten. Neufassung 1980 (Friedrich Dürrenmatt Werkausgabe 2), Zürich.

Elbern, Stephan (1990), „Das Verhältnis der spätantiken Kaiser zur Stadt Rom“, in: Römische Quartalsschrift für christliche Altertumskunde und für Kirchengeschichte 85, $19-49$.

Engels, David (2009), „Der Hahn des Honorius und das Hündchen der Aemilia. Zum Fortleben heidnischer Vorzeichenmotivik bei Prokop", in: Antike und Abendland $55,118-129$.

Ensoli, Serena/La Rocca, Eugenio (Hgg.) (2000), Aurea Roma. Dalla città pagana alla città cristiana, Rom.

Feichtinger, Barbara (1998), „Glaube versus Aberglaube. Der Untergang Roms in den Augen der Zeitgenossen", in: Chartulae. Festschrift für Wolfgang Speyer, Münster, $145-166$.

Fischer, Joseph (1947), Die Völkerwanderung im Urteil der zeitgenössischen kirchlichen Schriftsteller Galliens unter Einbeziehung des heiligen Augustinus, Heidelberg/Waibstadt.

Fraschetti, Augusto (1999a), „,Veniunt modo reges Romam“, in: William Victor Harris (ed.), The Transformation of Urbs Roma in Late Antiquity, Portsmouth, Rhode Island, 235-248.

Fraschetti, Augusto (1999b), La conversione da Roma pagana a Roma cristiana, Rom/ Bari.

Gibbon, Edward (2003), Verfall und Untergang des römischen Imperiums. Bis zum Ende des Reiches im Westen, Bd. 4, aus dem Englischen von Michael Walter, München.

Giglio, Stefano (1990), Il tardo impero d'Occidente e il suo senato, (Università degli Studi di Perugia. Pubblicazioni della Facoltà di Giurisprudenza), Neapel.

Gillett, Andrew (2001), „Rome, Ravenna and the Last Western Emperors“, in: Papers of the British School at Rome 69, 131-167.

Giorcelli Bersani, Silvia (Hg.) (2004), Romani e barbari. Incontro e scontro di culture. Atti del Convegno - Bra, $11-13$ aprile 2003, Torino.

Goetz, Hans-Werner/Patzold, Steffen/Welwei, Wilhelm (Hgg.) (2007), Die Germanen in der Völkerwanderung, Zweiter Teil, Darmstadt. 
Gregorovius, Ferdinand (1953), Geschichte der Stadt Rom im Mittelalter vom V. bis zum XVI. Jahrhundert, neu hrsg. von Waldemar Kempf, Bd. 1, Tübingen (die erste Ausgabe erschien 1859-1872).

von Haehling, Raban (1978), Die Religionszugehörigkeit der hohen Amtsträger des Römischen Reiches seit Constantins I. Alleinherrschaft bis zum Ende der Theodosianischen Dynastie, Bonn.

Heather, Peter J. (1991), Goths and Romans 332-489, Oxford.

Heather, Peter (2007), Der Untergang des Römischen Weltreichs, aus dem Englischen von Klaus Kochmann, Stuttgart (engl. 2005).

Hedrick, Charles W. Jr. (2000), History and Silence. Purge and Rehabilitation of Memory in Late Antiquity, Austin.

Heinzberger, Ferdinand (1976), Heidnische und christliche Reaktion auf die Krise des Weströmischen Reiches in den Jahren 395-410 n. Chr., Diss. Bonn.

Honoré, Tony (1998), Law in the Crisis of Empire 379-455 AD. The Theodosian Dynasty and its Quaestors. With a Palingenesia of Laws of the Dynasty, Oxford.

Jaffé, Philipp (Hg.) (1885), Regesta pontificum Romanorum ab condita ecclesia ad annum post Christum natum MCXCVIII, editionem secundam correctam et auctam auspiciis Gulielmi Wattenbach, curaverunt S. Loewenfeld, F. Kaltenbrunner, P. Ewald, Bd. 1, Leipzig.

Janßen, Tido (2004), Stilicho. Das weströmische Reich vom Tode des Theodosius bis zur Ermordung Stilichos (395-408), Marburg.

Johnson, Mark Joseph (2009), The Roman Imperial Mausoleum in Late Antiquity, Cambridge (Mass.) u.a.

Kiilerich, Bente/Torp, Hjalmar (1989), „Hic est: Hic Stilicho. The Date and Interpretation of a Notable Diptych", in: Jahrbuch des Deutschen Archäologischen Instituts $104,319-371$.

Klein, Richard (2006), „Honorius imperator“, in: Augustinus-Lexikon 3, 423-425.

Kulikowski, Michael (2009), Die Goten vor Rom, Darmstadt (engl. 2007).

Lejdegård, Hans (2002), Honorius and the City of Rome. Authority and Legitimacy in Late Antiquity, Uppsala.

Leppin, Hartmut (1996), Von Constantin dem Großen zu Theodosius II. Das christliche Kaisertum bei den Kirchenhistorikern Socrates, Sozomenus und Theodoret, Göttingen.

Lütkenhaus, Werner (1998), Constantius III. Studien zu seiner Tätigkeit und Stellung im Westreich 411-421, Bonn.

Magnani, Alberto (2002), Serena. L'ultima Romana, Mailand.

Martelli, Fabio (1981), „Onorio, Ravenna et la presa di Roma del 410“, in: Rivista storica dell'Antichità 11, 215-219.

Matthews, John (1990), Western Aristocracies and Imperial Court AD 364-425, Oxford (erste Auflage 1975).

Mayer, Emanuel (2002), Rom ist dort, wo der Kaiser ist. Untersuchungen zu den Staatsdenkmälern des dezentralisierten Reiches von Diocletian bis zu Theodosius II., Mainz.

Mazzarino, Santo (1942), Stilicone. La crisi imperiale dopo Teodosio, Rom.

Meier, Mischa/Patzold, Steffen (2010), August 410 - ein Kampf um Rom, Stuttgart.

Meischner, Jutta (1993), „Der Hochzeitskameo des Honorius“, in: Archäologischer Anzeiger, 613-619.

Millar, Fergus (2004), „De la frontière au centre: la monarchie centralisée de Théodose II (408-450 ap. J.-C.)“, in: Claude Moatti (éd.), La mobilité des personnes en Méditerranée de l'antiquité à l'époque moderne. Procédures de côntrole et documents d'identification, Rom.

Moorhead, Sam/Stuttard, David (2010), AD 410 the Year that Shook Rome, London. 
Nagl, Maria Assunta (1908), Galla Placidia, Paderborn.

Niquet, Heike (2000), Monumenta virtutum titulique. Senatorische Selbstdarstellung im spätantiken Rom im Spiegel der epigraphischen Denkmäler, Stuttgart.

O'Flynn, John Michael (1983), Generalissimos of the Western Roman Empire, Edmonton, Alberta.

Olovsdotter, Cecilia (2005), The Consular Image. An Iconological Study of the Consular Diptychs, Oxford.

Oost, Stewart Irvin (1968), Galla Placidia Augusta. A Biographical Essay, Chicago/ London.

Orlandi, Silvia (2004), Epigrafia anfiteatrale dell'Occidente Romano, VI. Roma. Anfiteatri e strutture annesse con una nuova edizione e commento delle iscrizioni del Colosseo, Rom.

Pietri, Charles (1976), Roma Christiana. Recherches sur l'Église de Rome, son organisation, sa politique, son idéologie de Miltiade à Sixte III (311-440), Rome.

Piganiol, André (Hg.) (1964), Le sac de Rome. Vue d'ensemble, Paris.

Platner, Samuel Ball (1929), completed and revised by Thomas Ashby, A Topographical Dictionary of Ancient Rom, Oxford (ristampata anastatica Roma 1965).

Purpura, Gianfranco (1993), „Il ,Colosso’ di Barletta ed il Codice di Teodosio II“, in: Atti dell'Accademia Romanistica Costantiniana, IX Convegno Internazionale, Perugia, 457-480.

PLRE I (1971): Jones, Arnold H. M. u. a. (Hgg.), The Prosopography of the Later Roman Empire, vol. I: 260-395, Cambridge u.a.

PLRE II (1980): Martindale, John R. (Hg.), The Prosopography of the Later Roman Empire, vol. II: 395-527, Cambridge u.a.

RIC X (1994): The Roman Imperial Coinage, vol. X, The Divided Empire and the Fall of the Western Parts AD 395-493, by John P. C. Kent, London.

Ruck, Brigitte (2001), „Eintracht und Sieg: zwei Brüder an der Macht. Die Arcadiusbasis auf dem Caesarforum“, in: Géza Alföldy/Silvio Panciera (Hgg.), Inschriftliche Denkmäler als Medien der Selbstdarstellung in der römischen Welt, Stuttgart, 209229.

Ruck, Brigitte (2007), Die Großen dieser Welt. Kolossalporträts im antiken Rom, Heidelberg.

Saint Augustin (2004), Sermons sur la chute de Rome, introduction, traduction et notes de Jean-Claude Fredouille, (Nouvelle Bibliothèque Augustinienne 8), Paris.

Seeck, Otto (1913), „Honorius“, in: RE VIII (16. Halbband), 2277-2292.

Seeck, Otto (1919), Regesten der Kaiser und Päpste für die Jahre 311 bis 476 n. Chr. Vorarbeit zur einer Prosopographie der christlichen Kaiserzeit, Stuttgart.

Silva-Tarouca, Carolus (1937), Epistularum Romanorum Pontificum ad vicarios per Illyricum aliosque episcopos collectio Thessalonicensis, Rom.

Sivan, Hagith (2011), Galla Placidia. The Last Roman Empress, Oxford u.a.

Spier, Jeffrey (2007), Late Antique and Early Christian Gems, Wiesbaden.

Stein, Ernst (1928), Geschichte des spätrömischen Reiches, Bd. 1, Vom römischen zum byzantinischen Staate (284-476 n. Chr.), Wien.

Steinby, Eva M. (ed.) (1993-2000), Lexicon Topographicum urbis Romae, 6 Bde., Rom.

Szidat, Joachim (2010), Usurpator tanti nominis. Kaiser und Usurpator in der Spätantike (337-476 n. Chr.), Stuttgart.

Thier, Andreas (2011), Hierarchie und Autonomie. Regelungstraditionen der Bischofsbestellung in der Geschichte des kirchlichen Wablrechts bis 1140, Frankfurt am Main. 
Thomas, Edit B. (1984), „Das Honoriusportrait aus Schützen am Gebirge. Honorius Augustus und die Quindezennalien des Theodosius I.", in: Wissenschaftliche Arbeiten aus dem Burgenland 69, 153-165.

Tillemont, Lenain de, Sébastien (1732), Histoire des Empereurs, Bd. 5, Venise.

Vincenti, Umberto (1992), La partecipazione del Senato all'amministrazione della giustizia nei secoli III-VI D.C. (Oriente e Occidente), Padova.

Walser, Gerold (1987), Die Einsiedler Inschriftensammlung und der Pilgerführer durch Rom (Codex Einsidlensis 326). Facsimile, Umschrift, Ubersetzung und Kommentar, Stuttgart.

Warland, Rainer (1994), „Status und Formular in der Repräsentation der spätantiken Führungsschicht", in: Mitteilungen des Archäologischen Instituts, Römische Abteilung $101,175-202$.

Wermelinger, Otto (1975), Rom und Pelagius. Die theologische Position der römischen Bischöfe im pelagianischen Streit in den Jahren 411-432, Stuttgart.

Wolfram, Herwig (1990), Die Goten. Von den Anfängen bis zur Mitte des sechsten Jahrhunderts. Entwurf einer historischen Ethnographie, 3. neubearb. Aufl., München. 